\title{
Electrical resistivity dynamics beneath a fractured sedimentary bedrock riverbed in response to temperature and groundwater-surface water exchange
}

\author{
Colby M. Steelman, Celia S. Kennedy, Donovan C. Capes, and Beth L. Parker \\ G360 Institute for Groundwater Research, College of Engineering and Physical Sciences, University of Guelph, \\ Guelph, Ontario, Canada \\ Correspondence to: Colby M. Steelman (csteelma@uoguelph.ca)
}

Received: 25 October 2016 - Discussion started: 1 November 2016

Revised: 4 May 2017 - Accepted: 27 May 2017 - Published: 29 June 2017

\begin{abstract}
Bedrock rivers occur where surface water flows along an exposed rock surface. Fractured sedimentary bedrock can exhibit variable groundwater residence times, anisotropic flow paths, and heterogeneity, along with diffusive exchange between fractures and rock matrix. These properties of the rock will affect thermal transients in the riverbed and groundwater-surface water exchange. In this study, surface electrical methods were used as a non-invasive technique to assess the scale and temporal variability of riverbed temperature and groundwater-surface water interaction beneath a sedimentary bedrock riverbed. Conditions were monitored at a semi-daily to semi-weekly interval over a full annual period that included a seasonal freeze-thaw cycle. Surface electromagnetic induction (EMI) and electrical resistivity tomography (ERT) methods captured conditions beneath the riverbed along a pool-riffle sequence of the Eramosa River in Canada. Geophysical datasets were accompanied by continuous measurements of aqueous specific conductance, temperature, and river stage. Time-lapse vertical temperature trolling within a lined borehole adjacent to the river revealed active groundwater flow zones along fracture networks within the upper $10 \mathrm{~m}$ of rock. EMI measurements collected during cooler high-flow and warmer lowflow periods identified a spatiotemporal riverbed response that was largely dependent upon riverbed morphology and seasonal groundwater temperature. Time-lapse ERT profiles across the pool and riffle sequence identified seasonal transients within the upper 2 and $3 \mathrm{~m}$ of rock, respectively, with spatial variations controlled by riverbed morphology (pool versus riffle) and dominant surficial rock properties (competent versus weathered rock rubble surface). While the pool
\end{abstract}

and riffle both exhibited a dynamic resistivity through seasonal cooling and warming cycles, conditions beneath the pool were more variable, largely due to the formation of river ice during the winter season. We show that surface electrical resistivity methods have the capacity to detect and resolve electrical resistivity transience beneath a fractured bedrock riverbed in response to porewater temperature and specific conductance fluctuations over a complete annual cycle.

\section{Introduction}

Fractured sedimentary bedrock represents an important source of water for many communities around the world. Although the effective porosity of rock is low relative to unconsolidated sediment, the existence of dense networks of interconnected fractures, dissolution-enhanced conduits, and karst features can result in productive yet heterogeneous and anisotropic flow systems. An exposed bedrock surface may exhibit greater variability in flow and transport properties as it is subjected to weathering and erosional processes, leading to very complicated groundwater recharge and discharge patterns. Fractured sedimentary rock is best conceptualized as a dual porosity system where fractures dominate flow, but remain connected to water stored in the porous matrix through advection and diffusion. Such conceptualizations of fracture flow and transport are routinely applied to groundwater resource (e.g., Novakowski and Lapcevic, 1998; Lemieux et al., 2009; Perrin et al., 2011) and contaminant transport studies (e.g., Zanini et al., 2000; Meyer et al., 2008; McLaren 
et al., 2012). Recent studies have extended these concepts to fluvial river environments (e.g., Singha et al., 2008; Toran et al., 2013a).

Groundwater-surface water interactions on the reach scale are conceptualized through gaining, losing, and flow-through interactions (Woessner, 2000). On the channel scale, microto-macro bedform variations result in variably scaled zones of surface water downwelling (recharge) and groundwater upwelling (discharge) (e.g., Binley et al., 2013; Käser et al., 2013). Groundwater temperature measurements are frequently used to monitor spatiotemporal variations in groundwater-surface water exchange or flux across riverbeds (e.g., Anderson, 2005; Irvine et al., 2016). Yet, very little is known about the existence and nature of hyporheic and groundwater-surface water mixing zones in fractured sedimentary bedrock, largely because these systems are very difficult to instrument using direct methods (e.g., drive point monitoring wells, seepage meters, thermistors), and the scale of the interaction may be very small or heterogeneous relative to unconsolidated sediment.

Hydrologic processes along a fractured bedrock river were explored by Oxtobee and Novakowski (2002), who concluded that groundwater-surface water interaction was restricted by poor vertical connectivity and limited exposure of horizontal bedding plane fractures. A subsequent numerical sensitivity analysis by Oxtobee and Novakowski (2003) confirmed that groundwater-surface water connectivity through discrete fractures would be highly variable in space and time, and would largely depend on fracture size or aperture, river stage, and the distribution of hydraulic head within the flow system. Fan et al. (2007) numerically explored the influence of larger-scale fracture orientations and geometries on the groundwater-flow system near a stream; they concluded that the base flow to a stream would be higher for streams aligned with fracture dip than those aligned with fracture strike. Therefore, groundwater-surface water interaction in a fractured bedrock environment will depend on stream-fracture alignment. Although these previous studies offered valuable insights into the magnitude of groundwater-surface water exchange, they were based on idealized fracture network conceptualizations, and did not consider the role of matrix porosity and potential exchanges between fractures and the porous matrix.

Electrical and electromagnetic methods such as groundpenetrating radar, electromagnetic induction, and electrical resistivity imaging are commonly used to characterize fluvial deposits (e.g., Naegeli et al., 1996; Gourry et al., 2003; Froese et al., 2005; Sambuelli et al., 2007; Rucker et al., 2011; Orlando, 2013; Doro et al., 2013; Crosbie et al., 2014). The capacity of time-lapse electrical resistivity imaging for conceptualization of groundwater transients in sediment is well-documented in the literature (e.g., Nyquist et al., 2008; Miller et al., 2008; Coscia et al., 2011, 2012; Cardenas and Markowski, 2011; Musgrave and Binley, 2011; Dimova et al., 2012; Wallin et al., 2013). Electrical imaging of natu- ral river systems perturbed by solute tracers has resulted in unprecedented visualizations of fluid flow (e.g., Ward et al., 2010a, b, 2012; Doetsch et al., 2012; Toran et al., 2013a, b; Harrington et al., 2014). More recent applications of electrical resistivity in karst undergoing surface water transients have shown how surface geophysics can unravel complex hydrologic processes in sedimentary bedrock environments (e.g., Meyerhoff et al., 2012, 2014; Sirieix et al., 2014), especially when site conditions limit the use of more invasive direct measurement methods.

While a variety of geophysical tools and techniques can measure flow and water chemistry in space and time (Singha et al., 2015), the most appropriate tool and approach will depend on the scale of interest. The vast majority of geophysical work within shallow river environments has utilized discrete temperature monitoring below the riverbed to detect vertical fluxes (e.g., White et al., 1987; Silliman and Booth, 1993; Evans et al., 1995; Alexander and Caissie, 2003; Conant Jr., 2004; Anderson, 2005; Hatch et al., 2006; Keery et al., 2007; Schmidt et al., 2007; Constantz, 2008). Recent advancements in distributed fiber-optic cables have improved spatial and temporal resolution of groundwater-surface water interactions (e.g., Slater et al., 2010; Briggs et al., 2012; Johnson et al., 2012).

Groundwater and surface water interaction can be monitored through changes in thermal gradient or electrolytic concentration (e.g., Norman and Cardenas, 2014), yet the scale and magnitude of these interactions will vary as a function of riverbed architecture and subsurface hydraulic conditions (Crook et al., 2008; Boano et al., 2008; Ward et al., 2012; Tinkler and Wohl, 1998), resulting in spatially dynamic exchange. These processes are further complicated by diel (e.g., Swanson and Cardenas, 2010) and seasonal (e.g., Musgrave and Binley, 2011) temperature fluctuations across a range of spatial scales, local transients such as precipitation events (e.g., Meyerhoff et al., 2012), river stage fluctuations (e.g., Bianchin et al., 2011), and controlled dam releases (e.g., Cardenas and Markowski, 2011). Relative to other non-invasive geophysical methods, electrical resistivity methods are more robust in their ability to provide information about temperature and solute fluctuations beneath actively flowing surface water bodies (e.g., Nyquist et al., 2008; Cardenas and Markowski, 2011; Ward et al., 2012; Meyerhoff et al., 2014) particularly in a time-lapse manner. Unlike conventional hydrogeological methods (e.g., screened or open "coreholes" - continuously cored boreholes), which may bias conduction in the fractures, surface electrical methods are sensitive to the bulk electrical conductivity of the formation, making them more suited for detection of processes between the open fractures or conduits and the porous matrix.

A hypothetical groundwater-surface water mixing zone in a porous fractured rock system (Fig. 1) will exhibit transience in water temperature and specific conductance as a result of changes in groundwater flow (recharge versus discharge), mixing of surface water and groundwater, seasonal 


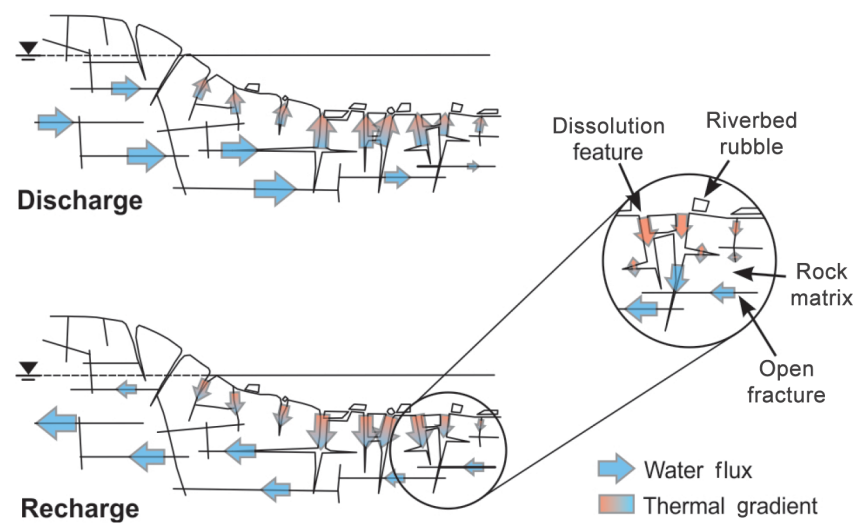

Figure 1. General conceptual model of the groundwater flow system beneath a fractured bedrock river. Groundwater-surface water mixing is controlled by open fractures and dissolution-enhanced features, with secondary exchanges (flux or diffusion) occurring between fractures and rock matrix.

atmospheric temperature fluctuations, and/or biogeochemical changes within the riverbed. Ward et al. (2010a) demonstrated how surface electrical methods sensitive to changes in water conductivity could be used to detect and quantify diffusive mass transport (exchange) between a mobile and immobile storage zone in a shallow riverbed. Our study uses a similar geophysical monitoring approach to assess the magnitude and scale of groundwater-surface water transience beneath a fractured bedrock riverbed based on the detection and characterization of geoelectrical dynamics over a complete annual cycle. Seasonal freezing and thawing of surface water bodies is an important process in mid-latitude climates; winter freeze-up will reduce base-flow contributions, while spring snow melt will result in a sudden and large increase in base flow to a river. Therefore, understanding the transient behaviours of the hydrogeologic system, including waterphase transformations, over a complete annual cycle will be critical to our understanding of the magnitude and spatial extent of groundwater-surface water exchange along fractured bedrock rivers. Given the challenges and costs associated with installing sensors within rock and heterogeneous flow system characteristics, minimally invasive surface and borehole geophysical methods offer an ideal alternative, and possibly a more effective approach for long-term groundwatersurface water monitoring of bedrock environments.

Our study examines the capacity of electrical imaging methods (i.e., electromagnetic induction and electrical resistivity) to monitor geoelectrical transients within a fractured sedimentary bedrock river to better understand groundwatersurface water transience over a complete annual cycle. To achieve this, seasonal variations in electrical resistivity distribution were measured across a $200 \mathrm{~m}$ reach of a bedrock river using a ground conductivity meter and time-lapse electrical resistivity measurements along two fixed transects intersecting a pool-riffle sequence. These geophysical surveys were supported by continuous measurements of groundwater and surface water temperature, specific conductance, and river stage. Our study shows that spatiotemporal resistivity dynamics were largely controlled by riverbed morphology in combination with seasonal changes in water temperature, and to a lesser degree electrolytic concentration. The formation of ground frost and basal ice strongly affected the electrical resistivity beneath the riverbed compared to intraseasonal dynamics (spring, summer, and fall). Observed geoelectrical changes beneath the riverbed appear primarily dependent on seasonal temperature trends exhibiting varying zones of influence (vertical and horizontal) across the pool and riffle section of the river. The riverbed was strongly susceptibility to seasonal atmospheric temperature fluctuations, which might have implications for biogeochemical processes or benthic activity.

\section{Background}

The Eramosa River - a major tributary of the Speed River within the Grand River watershed in Ontario, Canada - resides upon a regional bedrock aquifer of densely fractured dolostone with dissolution-enhanced conduits and karst features (e.g., Kunert et al., 1998; Kunert and Coniglio, 2002; Cole et al., 2009). Although this aquifer represents the sole source of drinking water for the region, the potential effects of increased groundwater pumping on the overlying bedrock river and surrounding ecosystems are not yet understood. This is largely due to a gap in our conceptual understanding of groundwater-surface water interaction in rivers that flow directly along sedimentary bedrock surfaces with exposed fracture networks. The fractured sedimentary bedrock exhibits a complex flow system due to variably connected fracture networks, dissolution-enhanced features, and variable bedrock exposure (Steelman et al., 2015a, b). The bulk of the flow will occur along the fracture networks, with highly variable head distributions; matrix storage could support equally complex biogeochemical processes and thermal dynamics through convective or diffusive exchange with open fractures or dissolution-enhanced features.

A focused geophysical investigation was carried out along a $200 \mathrm{~m}$ reach of the Eramosa River (Fig. 2). The study area was positioned at a bend in the river with relatively cleared vegetation along the southern shoreline and adjacent floodplain with exposed rock at the surface. A network of coreholes and streambed piezometers were installed across the site. Locally, the water table elevation corresponds to the surface water or stage elevation, resulting in vadose zone thicknesses from $<0.5$ to $2.0 \mathrm{~m}$ along the shorelines. The temperate southern Ontario climate subjects the river to a wide range of seasonal conditions, including high precipitation periods in spring and fall, hot and dry summers, and variable degrees of ground frost and surface water freeze-up during the winter months (Fig. 3a). 

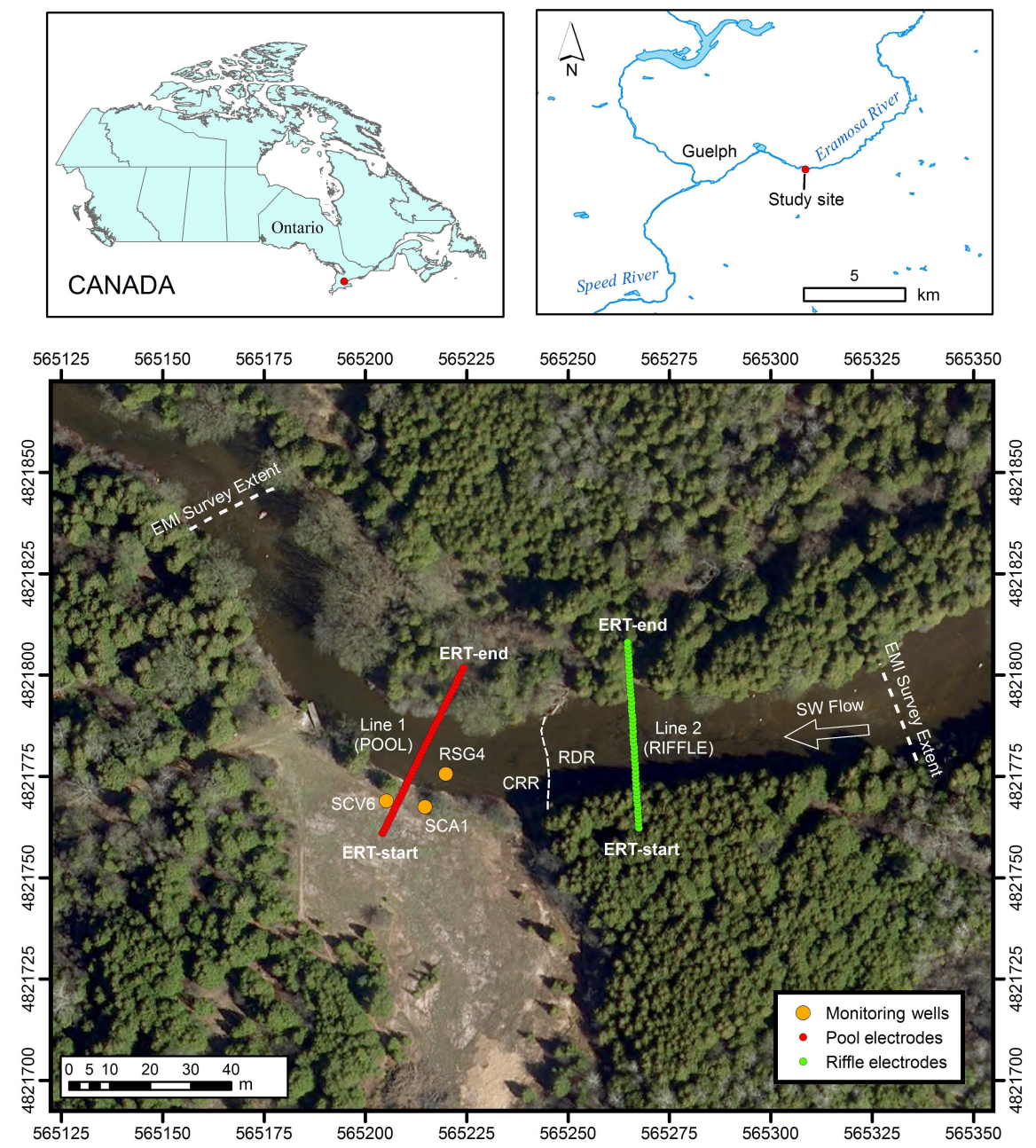

Figure 2. Field site located along the Eramosa River near Guelph, Ontario, Canada. The spatial extent of the electromagnetic induction (EMI) surveys, coreholes and groundwater-surface water monitoring points, and fixed electrical resistivity tomography (ERT) transects are shown relative to the riffle-pool sequence. The riverbed is described as either rubble-dominated riverbed (RDR) or competent rock riverbed (CRR) surface.

Locally, the river incises the Eramosa Formation by 2 to $3 \mathrm{~m}$, exposing abundant vertical and horizontal fractures with little to no alluvial sediment deposited along the riverbed (Fig. 3b). Regionally the Eramosa acts as a discontinuous aquitard unit (Cole et al., 2009); however, core logs collected at the study site show bedding plane and vertical joint set fractures spanning the entire $11 \mathrm{~m}$ sequence of Eramosa. This upper formation is underlain by approximately $3 \mathrm{~m}$ of the cherty, marble-like Goat Island formation, which exhibits high-angle fractures along cherty nodules near the Eramosa contact. The Goat Island is underlain by more than $15 \mathrm{~m}$ of Gasport Formation, which exhibits coral reef mounds of variable morphology. The rock matrix of the Gasport is visually more porous, with well-defined vugs, dissolution-enhanced features, and fewer fractures than the overlying Goat Island and Eramosa. A full description of these bedrock sequences can be found in Brunton (2009).
In this region, the winter season may be accompanied by the formation of ground frost and surface-water freezing. Seasonal freeze-up will consist of an ice crust layer on the surface of the water and the possible formation of basal ice along the riverbed (Stickler and Alfredsen, 2009). The latter phenomenon can occur during extreme atmospheric cooling over turbulent water bodies, resulting in super-cooled water $\left(<0^{\circ} \mathrm{C}\right)$ that rapidly crystalizes to form frazil (i.e., tiny ice particles with adhesive characteristics); these crystals can flocculate to form slush, which adheres and accumulates on the substrate, forming a basal ice layer. 
(a)

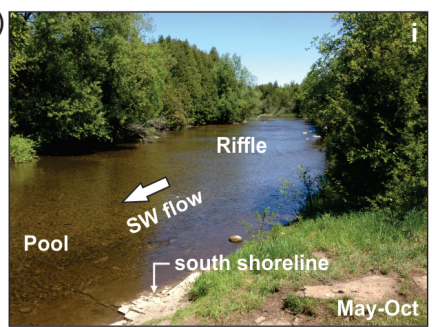

(b)

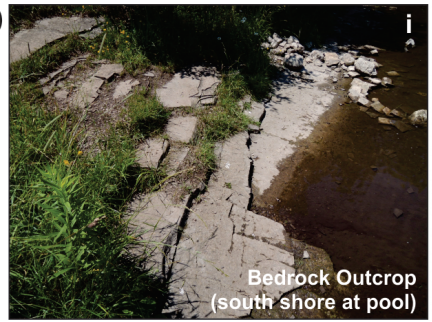

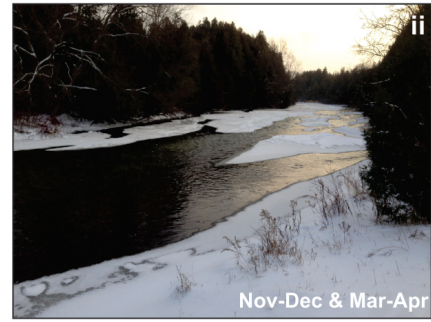
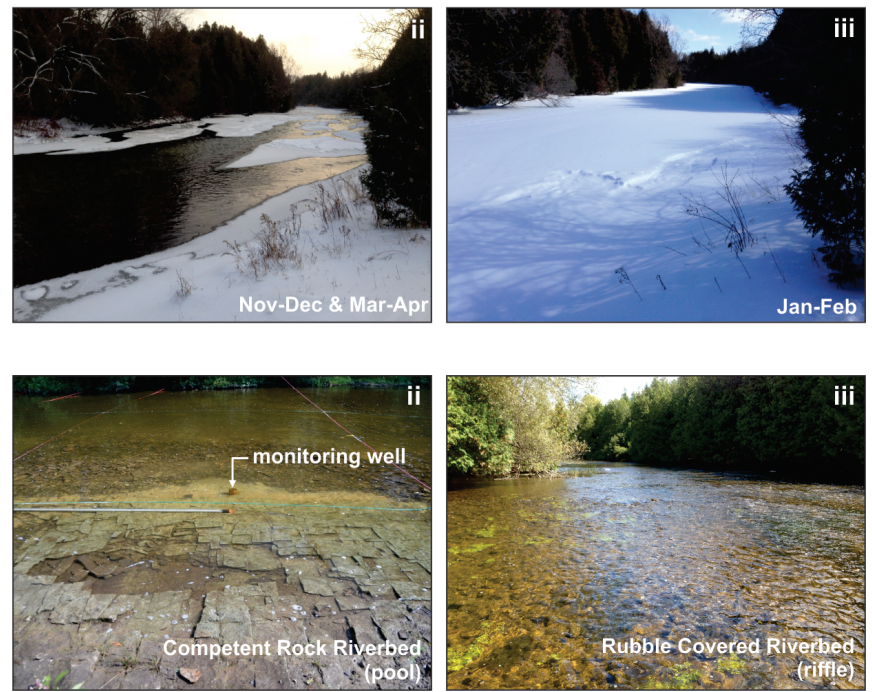

Figure 3. (a) Images of the river during monitored study period. (b) Examples of vertical and horizontal fracturing within pool and rubble covered portions of the riverbed bedrock.

\section{Methods}

\subsection{Electrical properties}

Electrical resistivity methods are based upon Ohm's Law $(R=\Delta V / I)$. In the case of a homogeneous half-space, the electrical resistance $(R)$ of the subsurface is determined by measuring the potential difference $(\Delta V)$ across a pair of "potential" electrodes due to an applied current $(I)$ across a separate pair of "current" electrodes a certain distance away. The measured $R(\Omega)$ across a unit volume of the earth can be converted to apparent resistivity $(\Omega \mathrm{m})$ using a specific geometric factor that compensates for varying electrode array geometry (Reynolds, 2011). Apparent resistivity measurements are commonly interpreted using tomographic inversion techniques, whereby measured data are reconstructed from forward models of an optimized physical parameter distribution (Snieder and Trampert, 1999; Loke et al., 2013). Although data inversion techniques are standard practice in the interpretation of most geophysical data, the model that best matches the measured data is not necessarily an exact representation of the subsurface. Here, the inversion process ultimately yields a smoothed representation of the true parameter distribution.

The bulk electrical resistivity (i.e., inverse of conductivity) of a porous medium can be calculated through an empirical relationship known as Archie's law (Archie, 1942):

$\rho_{\mathrm{b}}=\rho_{\mathrm{w}} \phi^{-m} S_{\mathrm{w}}^{-n}$,

where the resistivity of the bulk formation $\left(\rho_{\mathrm{b}}\right)$ is related to the resistivity of the pore water $\left(\rho_{\mathrm{w}}\right)$, porosity of the medium $(\phi)$ raised to the negative power $(m)$ that represents the degree of pore cementation, and fraction of pores containing water $(S)$ raised to the negative power $(n)$ that accounts for the connectedness of the pore water (Glover, 2010). This relationship carries a number of simplifying assumptions: the most significant being that the current flow is entirely electrolytic. While more sophisticated formulations of Archie's Law incorporating interfacial conduction can be found in the literature (e.g., Rhoades et al., 1976; Waxman and Smits, 1968; Glover, 2010), Eq. (1) is considered to be a reasonable approximation for this type of environment. Equation (1) is used in this study to evaluate the impact of observed groundwater and surface water aqueous conductivity variations on the bulk formation resistivity. Here, a value of 1.4 was used for the constant $m$, which is considered reasonable for fractured dolostone (Doveton, 1986), while $S$ is considered to be equal to unity (i.e., fully saturated). It should be noted that the relative impact of aqueous conductivity changes on the bulk formation resistivity may vary with clay content and pore connectivity due to intrinsic deviations in the $m$ value (Worthington, 1993). Furthermore, orientated fracture networks may result in an anisotropic resistivity response (Steelman et al., 2015b); however, these static properties of the rock will not impact relative changes in resistivity at a fixed location.

The electrolytic (fluid phase) resistivity will depend on the concentration and composition of dissolved ions, and viscosity of the pore water (Knight and Endres, 2005). Increasing ion concentrations and temperature will lead to a reduction in formation resistivity. Empirical evidence has shown that resistivity can decrease anywhere from 1 to $2.5 \%$ per ${ }^{\circ} \mathrm{C}$ (Campbell et al., 1948; Keller, 1989; Brassington, 1998). The effects of temperature on our resistivity signals were determined using Arps' law (Arps, 1953):

$\rho_{\mathrm{w} 2}=\frac{\rho_{\mathrm{w} 1}\left(T_{1}+21.5\right)}{\left(T_{2}+21.5\right)}$ 
where $\rho_{\mathrm{w}}(\Omega \mathrm{m})$ and $T\left({ }^{\circ} \mathrm{C}\right)$ represent the resistivity and temperature of the water at two points. This formulation was developed from a least-squares fit to the conductivity of a $\mathrm{NaCl}$ solution ranging from 0 to $156^{\circ} \mathrm{C}$; however, the exact relationship between fluid conductivity and temperature will depend on the composition of the electrolytic solution (Ellis, 1987).

\subsection{Bedrock lithology, fractures, and porosity}

The geology was characterized through a series of vertical and angled coreholes along the southern shoreline that were advanced into upper Gasport Formation. These drilling activities were part of a broader hydrogeological investigation of groundwater flow and fluxes along the river. A network of riverbed piezometers, bedrock stage gauges, and flux measurement devices were installed between 2013 and 2014 within the pool. Locally, the riverbed morphology can be distinguished in terms of the amount of bedrock rubble or weathered rock fragments covering the exposed rock surface. Figure 2 shows the transition from a rubble-dominated riverbed (RDR) to a more competent rock riverbed (CRR); this boundary roughly corresponds to the riffle-pool transition.

Geophysical measurements were supported by temperature, specific conductance of the fluid, and river stage elevation collected at nearby monitoring points (Fig. 2). The geologic and hydrogeologic data were obtained from a river stage gauge (RSG4), a vertical corehole (SCV6) drilled to a depth of $10.9 \mathrm{~m}$, and an angled corehole (SCA1) drilled to a vertical depth of $31.8 \mathrm{~m}$. The angled corehole plunges at $60^{\circ}$ and is orientated at $340^{\circ}$, and therefore, plunges beneath the river with a lateral displacement of $21 \mathrm{~m}$. Coreholes were drilled using a small-diameter portable Hydracore Prospector $^{\mathrm{TM}}$ drill with a diamond bit (NQ size: $47.6 \mathrm{~mm}$ core and $75.7 \mathrm{~mm}$ corehole diameter) and completed with steel casings set into concrete to a depth of $0.6 \mathrm{~m}$ below ground surface (b.g.s.). All coreholes were sealed using a flexible impermeable liner filled with river water $\left(\mathrm{FLUTe}^{\mathrm{TM}}\right.$ Flexible Liner Underground Technologies, Alcalde, New Mexico, USA; Keller et al., 2014).

The SCA1 rock core was logged for changes in lithology, vugs, and fracture characteristics, intensity and orientation, including bedding plane partings. Rock core subsamples were extracted for laboratory measurements of matrix porosity using the following procedure: sample was oven dried at $40{ }^{\circ} \mathrm{C}$; dimensions and dry mass were recorded; samples were evacuated in a sealed chamber and imbibed with deionized water; the sample chamber was pressurized to 200 to $300 \mathrm{psi}$ for $15 \mathrm{~min}$; and samples were blotted and weighed to obtain saturated mass. Open coreholes were logged using an acoustic (QL40-ABI) and an optical (QL40-OBI) borehole imager (Advanced Logic Technologies, Redange, Luxembourg) to characterize the fracture network.

\subsection{Pressure, temperature, specific conductance, and river flow}

Temperature, specific conductance, and hydraulic pressure data were recorded using a CTD-Diver ${ }^{\mathrm{TM}}$ (Van Essen Instruments, Kitchener, Canada) deployed within RSG4 (surface water) and SCV6 (groundwater) at a depth of $10.5 \mathrm{~m}$ b.g.s. The transducer in SCV6 was placed near the bottom of the open corehole prior to being sealed with an impermeable liner, thereby creating a depth-discrete groundwater monitoring point. Surface water data were recorded through the full study period while deeper bedrock conditions were recorded from early September 2014 through late May 2015. All measurements were collected at 15 min intervals.

Vertical temperature profiles were additionally collected along the inclined sealed corehole water column of SCA1 from 4 September 2014 to 22 May 2015 using an RBRsolo ${ }^{\mathrm{TM}}$ temperature logger paired with a RBRsolo ${ }^{\mathrm{TM}}$ pressure logger (RBR Limited, Ottawa, Canada). These data were recorded at $0.5 \mathrm{~s}$ intervals while the sensors were manually lowered into the water column using a fiberglass measuring tape at a rate of 0.02 to $0.03 \mathrm{~m} \mathrm{~s}^{-1}$. Barometric pressure was collected at the site using a Baro-Diver ${ }^{\mathrm{TM}}$ (Van Essen Instruments, Kitchener, Canada). These temperature sensors can resolve changes to $0.5 \times 10^{-4}{ }^{\circ} \mathrm{C}$ with a full-scale response time of $99 \%$ in $2 \mathrm{~s}$.

Rainfall was recorded at the University of Guelph Turfgrass Institute, located $2 \mathrm{~km}$ northwest of the site, while snowfall accumulation was obtained from the Region of Waterloo Airport roughly $18 \mathrm{~km}$ southwest of the site. Hourly mean river flux was recorded $900 \mathrm{~m}$ upstream at the Watson Road gauge operated by the Grand River Conservation $\mathrm{Au}-$ thority. A summary of the weather and river flux data are provided in Fig. 4.

\subsection{Riverbed electrical resistivity}

\subsubsection{Spatial electrical resistivity mapping}

Spatial riverbed resistivity distribution was measured using a Geonics EM-31 ground conductivity meter (Geonics, Mississauga, Canada) during a seasonally cool and warm period: mid-summer (low-stage) conditions on 7 July 2014 and early spring (high-stage) conditions on 3 April 2013. Measurements were collected at a rate of 3 readings per second with the device operated in vertical dipole mode held $\sim 1 \mathrm{~m}$ above the riverbed. The effective sensing depth of this instrument in vertical dipole mode is approximately $6 \mathrm{~m}$ (cumulative depth), and it is minimally sensitive to conditions above the ground surface (McNeil, 1980). Data were recorded along roughly parallel lines spaced $\sim 1.75 \mathrm{~m}$ apart orthogonal to the river orientation, with the coils aligned parallel to surface water flow direction. Water depths over the investigated reach varied from $<0.1 \mathrm{~m}$ in the riffle during low-flow to nearly $1 \mathrm{~m}$ in the pool during high-flow conditions. Datasets were 


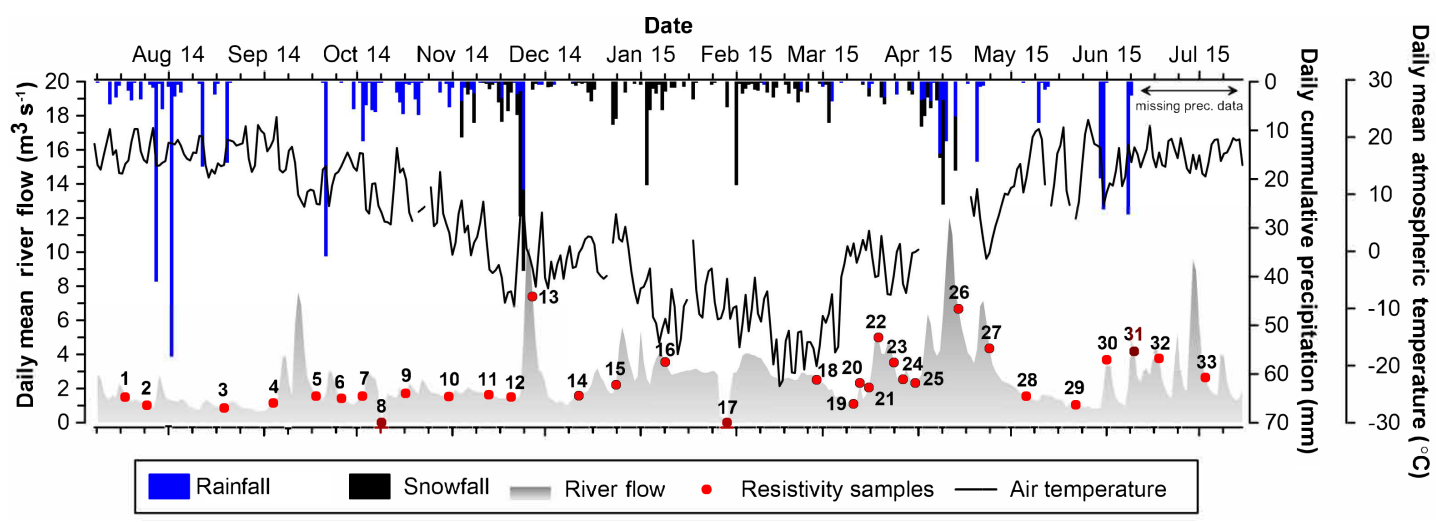

Figure 4. Continuously monitored atmospheric conditions and river flow from Watson Gauge during the study period, with superimposed resistivity geophysical measurement events between 18 July 2014 and 3 July 2015. Note: snowfall is presented as snow water equivalent.

filtered for anomalous outliers prior to minimum curvature gridding.

\subsubsection{Time-lapse electrical resistivity imaging}

Surface electrical resistivity measurements were collected along two fixed transects orientated orthogonal to the river (Fig. 2), capturing conditions within a pool and riffle sequence (Fig. 3). Line 1 was positioned downstream over a deeper pool section with more substantial bedrock incision into a competent bedrock surface (Fig. 3b.i and b.ii), while line 2 was situated upstream over a shallower riffle section blanked by bedrock rubble fragments with less bedrock incision (Fig. 3b.iii).

For this study, resistivity cables were constructed using a pair of 25 multicore cables (22 gauge strained wire, $600 \mathrm{~V}$ rating) wound within a PVC jacket. The PVC jacket was split open every metre to expose and cut out a single wire that was connected to an audio-style banana plug. Spliced sections of outer PVC jacket were resealed using heat shrink tubing and silicon. This process yielded two 24-channel cables, each connected to a single multi-pin connector for direct data logger communication. Electrodes were constructed from halfinch diameter stainless steel rod cut to $15 \mathrm{~cm}$ lengths. A hole was drilled on one end of the electrode to receive the banana plug connector. Given the exposed bedrock across the site, a half-inch hole was drilled into the rock at $1 \mathrm{~m}$ intervals along the ground surface. In some cases, electrodes were buried beneath a rubble zone of the riverbed, or were pushed into a thin layer of sediment. On the shorelines, electrodes were fully implanted into the rock along with a few teaspoons of bentonite clay to minimize contact resistance. Each monitoring line was instrumented with dedicated electrodes and cables that remained in place for the duration of the study.

Resistivity measurements were recorded using a Syscal Junior Switch 48 (Iris Instruments, Orléans, France) resistivity meter. A Wenner array was selected for its higher $S / N$ ratio. A dipole-dipole array was tested but found to be very susceptible to noise (i.e., bad data points resulting from low potentials); this can be attributed to the high-contact resistances with rock combined with the instrument's more moderate power capability ( $\max 400 \mathrm{~V}, 1.3 \mathrm{~A})$. Although the Wenner array geometry resulted in a stronger signal (i.e., where potentials are measured across a pair of electrodes located between the current electrodes), it was less sensitive to lateral variations across the riverbed and did not permit the collection of a reciprocal dataset, which could have been used to assess potential measurement errors (e.g., Slater et al., 2000). Surface resistivity data were recorded on a semi-daily to semi-weekly interval from 18 July 2014 to 3 July 2015 covering a complete annual cycle, which included a seasonal freeze-thaw cycle, and numerous wettingdrying events accompanied by large river stage fluctuations. The timing of resistivity measurement events are shown along the river flow data in Fig. 4. Resistivity measurements were generally recorded between 08:00 LT and 13:00 LT.

Measured apparent resistivity data were manually filtered to remove erroneous data points prior to being inverted using RES2DINV v.3.59 (Geotomo Software, Malaysia), which uses the Gauss-Newton least-squares method (Loke and Dahlin, 2002). For this study, a robust inversion scheme was used with a moderate dampening factor applied at the riffle and a slightly higher dampening factor at the pool. These dampening factors were chosen based on the resistivity contrasts observed along the rock surface, along with intermittently noisy measurements at the pool; the width of the model cells were set to half the electrode spacing (i.e., model refinement) to help suppress the effects of large surface resistivity variations on the inversion process. All other parameters within the program were optimized to compensate for high noise and large resistivity contrasts, while achieving the lowest possible model root mean squared (RMS) error (Loke, 2002). Each model was independently inverted with a defined surface water boundary (i.e., stage height above the submerged electrodes) and true aqueous resistivity, both of which were fixed for each model inversion. The same set of 
initial inversion parameters was applied to all datasets collected along a given line. Model convergence typically occurred within 8 iterations.

Temporal variations in bedrock resistivity were assessed within $5 \mathrm{~m}$ wide $\times 2.5 \mathrm{~m}$ deep zones beneath the riverbed based on a resistivity index (RI) calculation. This enabled comparison of datasets with different magnitudes of resistivity variation. The RI was defined as follows:

$\mathrm{RI}_{i, j}=\frac{\mathrm{MZR}_{i, j}-\mathrm{MAR}}{\mathrm{MAR}}$,

where $\mathrm{RI}_{i, j}=$ resistivity index for the $i$ th zone on the $j$ th sample date; $\mathrm{MZR}_{i, j}=$ mean zone resistivity for the $i$ th zone on the $j$ th sample date; MAR $=$ mean annual resistivity of the entire profile across the full time series for the pool or riffle.

\section{Results}

\subsection{Bedrock fracture network, temperature, and specific conductance}

Formation contacts of the Eramosa-Goat Island and the Goat Island-Gasport formations were identified in the core at depths of 8.6 and $13.0 \mathrm{mb}$ b.g.s., respectively (Fig. 5a). Fractures beneath the river were predominantly horizontal to slightly dipping $\left(<10^{\circ}\right)$, and most abundant in the Eramosa and Goat Island formations. Although vertical and sub-vertical fractures $\left(>10^{\circ}\right)$ were relatively less abundant than bedding plane fractures, they were more uniformly distributed with depth. These high-angle fractures terminate at the surface as vertical joint sets along two regional orientations: 10 to $20^{\circ}$ north-northeast and 280 to $290^{\circ}$ westnorthwest (Fig. 3b.ii). Matrix porosities from the corehole ranged from 0.5 to $5 \%$ with the lowest porosities observed along the highly weathered riverbed surface and lower portion of the Eramosa Formation. Hydraulic head data collected in the river and at the base of SCV6 (10.5 m b.g.s.) suggest a seasonally sustained downward gradient ranging from 0.21 to 0.26 at the pool; however, this does not necessarily reflect conditions proximal to the streambed.

Vertical temperature profiling within the static water column of the FLUTe ${ }^{\mathrm{TM}}$ lined SCA1 corehole from 4 September 2014 to 22 May 2015 captured seasonal fluctuations in ambient groundwater temperature to depths up to $20 \mathrm{~m}$ (Fig. 5b), thereby delineating the vertical extent of the heterothermic zone. Temperatures inside the liner ranged from $18^{\circ} \mathrm{C}$ in late summer to $5^{\circ} \mathrm{C}$ in mid-winter. Although fluctuations were observed along the entire $20 \mathrm{~m}$ profile, the bulk of the variations (short- and long-period) were observed in the upper $10 \mathrm{~m}$ b.g.s.

Previous studies using ambient temperature profiling in lined coreholes (Pehme et al., 2010, 2014) examined the effects of active groundwater flow around static water columns.

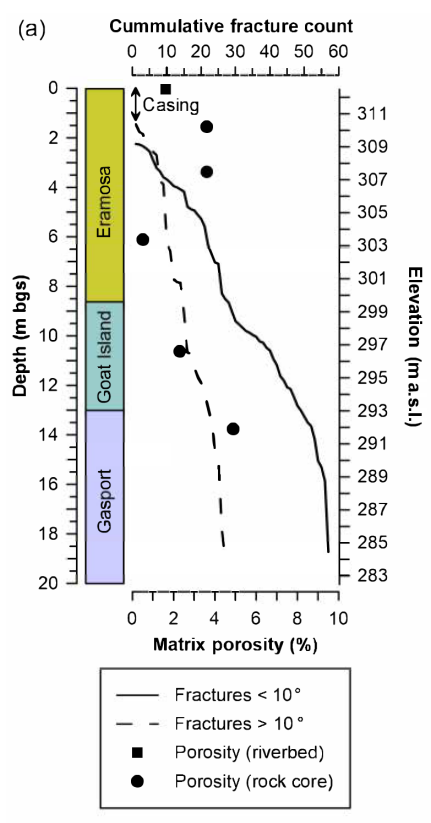

(b)
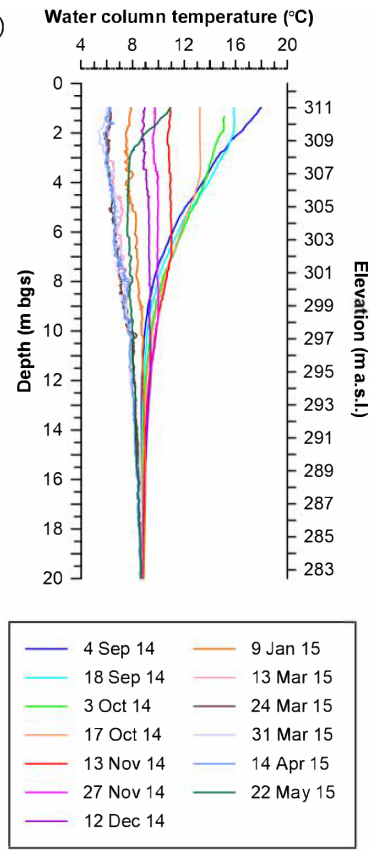

Figure 5. (a) Interpreted rock core from SCA1 (angled corehole plunging at $60^{\circ}$ with an azimuth of $340^{\circ}$ ). Fracture frequency and orientations were obtained using an acoustic televiewer log, while matrix porosity measurements were obtained from subsamples of the continuous core. (b) Corehole temperature profiles of the SCA1 Flute $^{\mathrm{TM}}$ sealed water column.

Pehme et al. (2010) demonstrated how a lined water-filled corehole in thermal disequilibrium with the surrounding formation would exhibit more short-period temperature perturbations along its vertical profile than an equilibrated water column within zones of active groundwater flow. Here, the onset of winter seasonal conditions ( 9 January through 31 March 2015) cooled the corehole water column near the ground surface, resulting in density-driven convection within the column and leading to thermal disequilibrium with respect to the surrounding bedrock which then results in subtle temperature perturbations as the water column cooled toward $5^{\circ} \mathrm{C}$. The magnitude and frequency of the perturbations observed in Fig. 5b during these cooler periods correspond to areas of increased fractures (Fig. 5a) supporting active groundwater flow.

Specific conductance and temperature of surface water (RSG4) and groundwater (SCV6) corresponding to geophysical sampling events (Fig. 4) are presented in Fig. 6. These data indicate that surface water specific conductivity varied within a much narrower range than the actual (uncompensated) conductivity, which includes the effects of temperature. While the overall impact of temperature and ionic concentration on the specific conductance of surface water were similar (i.e., equivalently dynamic), variations associated with ionic concentration appear more erratic, exhibiting sharper fluctuations over shorter periods of time. For in- 


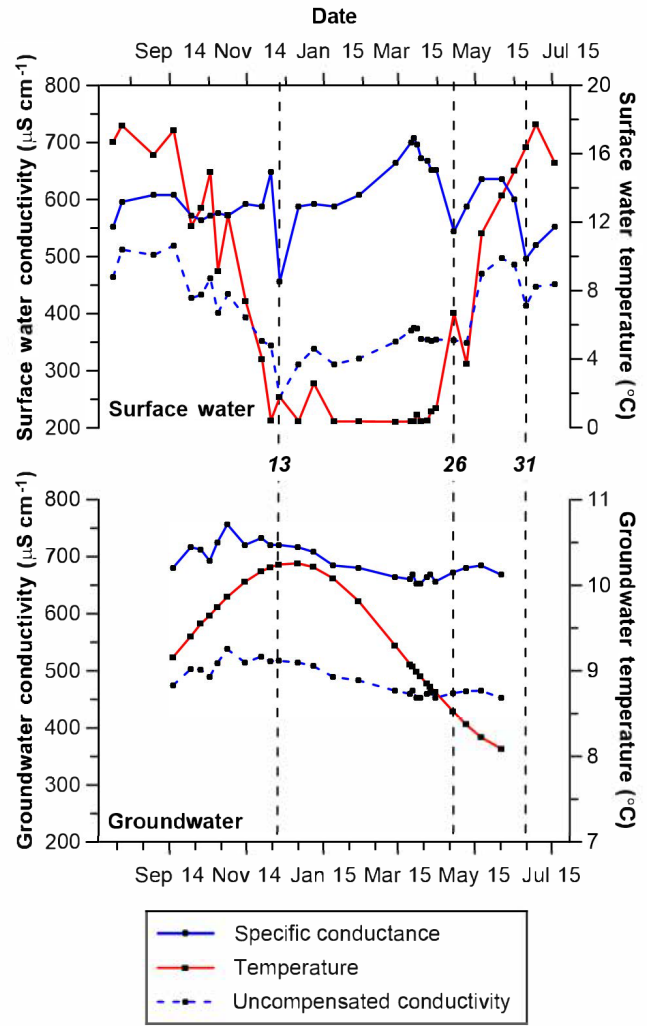

Figure 6. Specific conductance, temperature, and uncompensated aqueous conductivity of surface water at RSG4 and groundwater at the bottom of SCV6 (10.5 m b.g.s.). Uncompensated conductivity represents the actual conductivity of the porewater after reincorporating the effect of temperature using the sensor's internal temperature-conductivity correction factor.

stance, major precipitation events coinciding with measurement events 13, 26, and 31 (refer to Fig. 4) were accompanied by short-period reductions in surface water conductivity and increases in temperature. Seasonal atmospheric temperature trends resulted in more gradual, yet sustained reductions in aqueous conductivity. In comparison, the groundwater specific conductance at $10.5 \mathrm{mb}$.g.s. was comparatively stable during the study period, exhibiting a moderate temperaturedriven decline superimposed by shorter-period fluctuations associated with ion concentration.

Figure 7 shows the potential impact of these observed specific conductivity and temperature variations (based on Figs. 5b and 6) on the bulk formation resistivity using Eqs. (1) and (2) for three representative porosity values. Porosities of 1 and $5 \%$ correspond to the values obtained in the core, while a porosity of $35 \%$ is assumed to represent the maximum porosity of a weathered or broken rubble zone (i.e., unconsolidated porous sediment). These calculations indicate that variations in temperature will likely be the primary driver in formation resistivity dynamics. For instance, water temperature could affect the formation resistiv-

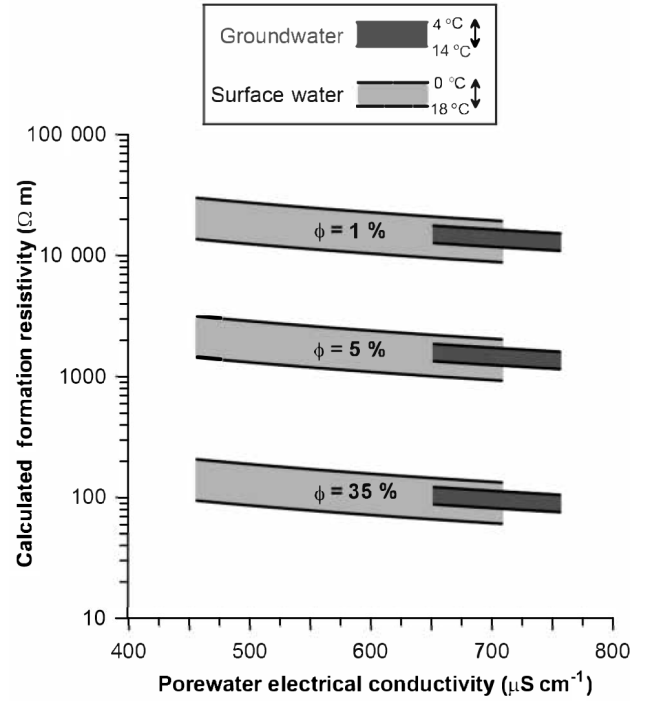

Figure 7. Calculated formation resistivity based on Eq. (1) and measured variations in surface water and groundwater electrical conductivity, including effects of temperature based on Eq. (2). A cementation factor of 1.4 was used to represent the fractured dolostone bedrock. Measured water conductivity and temperature were obtained from CTD-Diver ${ }^{\mathrm{TM}}$ sensors deployed in RSG4 (surface water) and SCV6 (groundwater at a depth of $8 \mathrm{mb}$ b.g.s.), and the continuous $\mathrm{RBR}^{\mathrm{TM}}$ temperature profiles shown in Fig. 5b. These data show the potential range in formation resistivity based on the measured range in specific conductance, along with the potential impact of temperature for three different porosity values. Porosities of 1 and $5 \%$ correspond to the range measured in the core, while a value of $35 \%$ would be representative of a rubble zone.

ity by as much as $46 \%$ (between isotherms), based on the observed range in groundwater and surface water temperatures. In comparison, measured aqueous conductivity ranges (along an isotherm) for groundwater and surface water would affect the formation resistivity by 18 and $36 \%$, respectively. These maximum temperature effects represent end-member conditions for a given specific conductance and effective porosity estimate.

\subsection{Sub-riverbed electrical resistivity distribution}

Two ground conductivity surveys were conducted across the riverbed surface to assess spatial variability in bulk formation resistivity and its relationship to riverbed morphology (e.g., pool versus riffle): resistivity snapshots were collected on 7 July 2014 during low-flow conditions $\left(1.30 \mathrm{~m}^{3} \mathrm{~s}^{-1}\right)$ and on 3 April 2013 during high-flow conditions $\left(6.81 \mathrm{~m}^{3} \mathrm{~s}^{-1}\right)$ (Fig. 8a). The percentage change in resistivity from lowto high-stage periods is shown in Fig. 8b. The daily average river flows for the years 2013 and 2014 were 3.5 and $3.3 \mathrm{~m}^{3} \mathrm{~s}^{-1}$, respectively. 
(a)

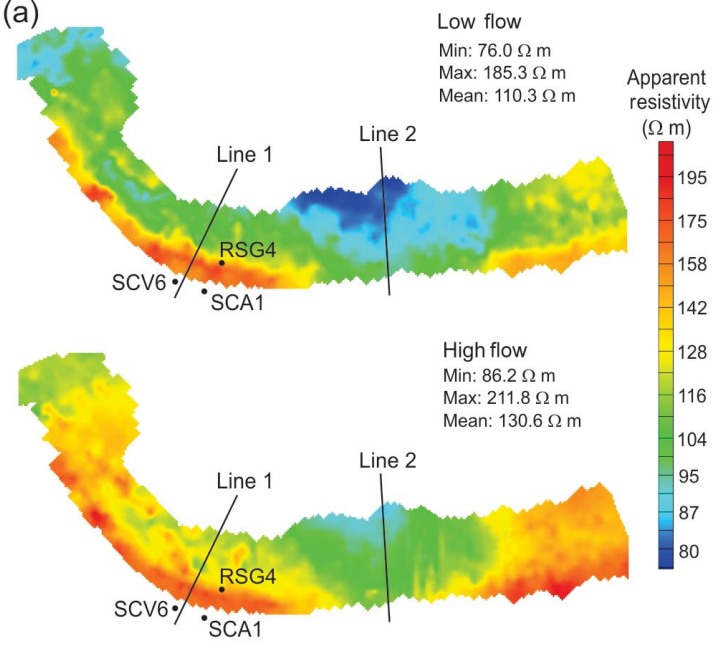

(b)

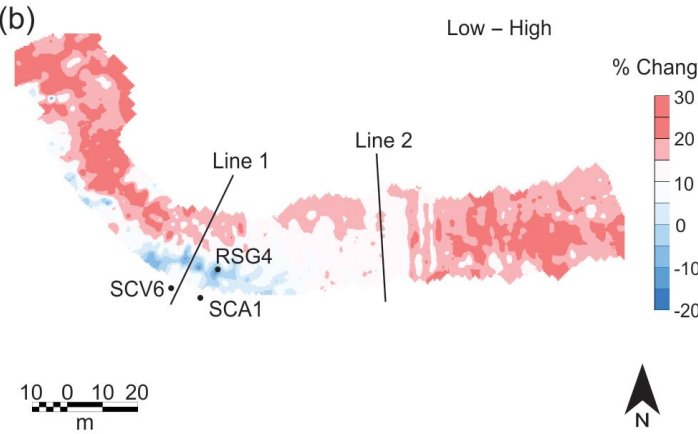

Figure 8. Riverbed resistivity obtained using an EM-31 ground conductivity meter during low-flow (low-stage) conditions on 7 July 2014 and high-flow (high-stage) conditions on 3 April 2013. (b) Percentage change in apparent resistivity from low- to highstage periods.

Two main observations can be made from the changes observed between warmer low-flow and cooler high-flow conditions. First, the southern shoreline exhibited a 10 to $15 \%$ reduction in resistivity along the southern shoreline within the pool and along the cut bank (outer edge of the elbow). These areas were characterized by more competent rock with exposed bedding plane fractures and vertical joints (Fig. 3b.i). Secondly, a broader and more variable increase in resistivity upwards of 20 to $25 \%$ was observed northward into the thalweg, along the slip-off slope (inner edge of the elbow) and the eastern and western portions of the reach; the rock surfaces in these areas were more weathered with large irregular rock fragments and dissolution features, as well as limited exposure of horizontal bedding plane fractures. A lower resistivity zone (blue area) was identified upstream within the northern portion of the riffle section (Fig. 3b.iii). The riffle portion of the river was also accompanied by a break in the high resistivity trend observed along the southern shoreline. A lower average resistivity was observed during warmer low-flow conditions, indicating that a portion of the response may be dependent on formation temperature (i.e.,
5 to $20^{\circ} \mathrm{C}$ fluctuations). However, the reduction in resistivity along the cut bank during cooler high-stage periods indicates an increase in the specific conductance of the pore fluid, which would be consistent with increased baseflow and groundwater discharge to the river.

\subsection{Time-lapse electrical resistivity imaging}

\subsubsection{Electrical resistivity models}

Figure 9 provides a summary of the inverted model results at the pool (Fig. 9a) and riffle (Fig. 9b) sections for the full study period. The mean inverted model resistivity and data range for each sample event is presented along with the number of apparent resistivity data points removed from the dataset prior to inversion, and the root mean squared error of the inverted model. The partially frozen and frozen ground conditions were accompanied by higher signal noise due to a systematic increase in electrode contact resistance and reduction in pore fluid connectivity (liquid water saturation near the surface); here, lower potentials resulted in more frequent failed measurement, which had to be removed from the dataset prior to inversion. Therefore, the noisier datasets collected in these periods were accompanied by higher model RMS errors. A subset of the inverted resistivity models over the annual cycle (i.e., Fig. 9a-h) are shown in Fig. 10. These snapshots capture the spatiotemporal evolution of predominant geoelectrical conditions beneath the riverbed.

Spatial electrical resistivity data were highly variable across the pool (Fig. 10a-h). The highest resistivities were observed along the southern shoreline, which coincided with the presence of competent bedrock (Fig. 3b.i) with bedding plane fractured and vertical joint sets. Similarly resistive conditions extended southward onto the floodplain. Subsurface conditions became less resistive toward the northern shoreline, which coincided with the presence of increased vertical fracturing and dissolution-enhanced features, mechanically broken or weathered bedrock, and a thin layer of organic rich sediment alongside the northern shoreline and floodplain. Initial surveys conducted across the pool on 25 July 2014 identified a relatively low resistivity zone $(<1000 \Omega \mathrm{m})$ extending $2 \mathrm{~m}$ beneath the riverbed that spanned the full width of the river. Measurements on 26 September through 24 December 2014 captured the retraction of this zone toward the northern shore. During this period the resistivity across the full transect increased only slightly. The onset of frozen ground and river conditions on 29 January 2014 resulted in an abrupt shift in the resistivity distribution. A high resistivity zone formed above the water table across the southern floodplain and was accompanied by an increase in resistivity across the full river profile. It is important to note that these frozen periods were accompanied by higher model RMS errors, and thus our interpretation of these data focus on longperiod trends. The formation of river ice (visually observed basal and surface ice) may have altered the true geometry of 

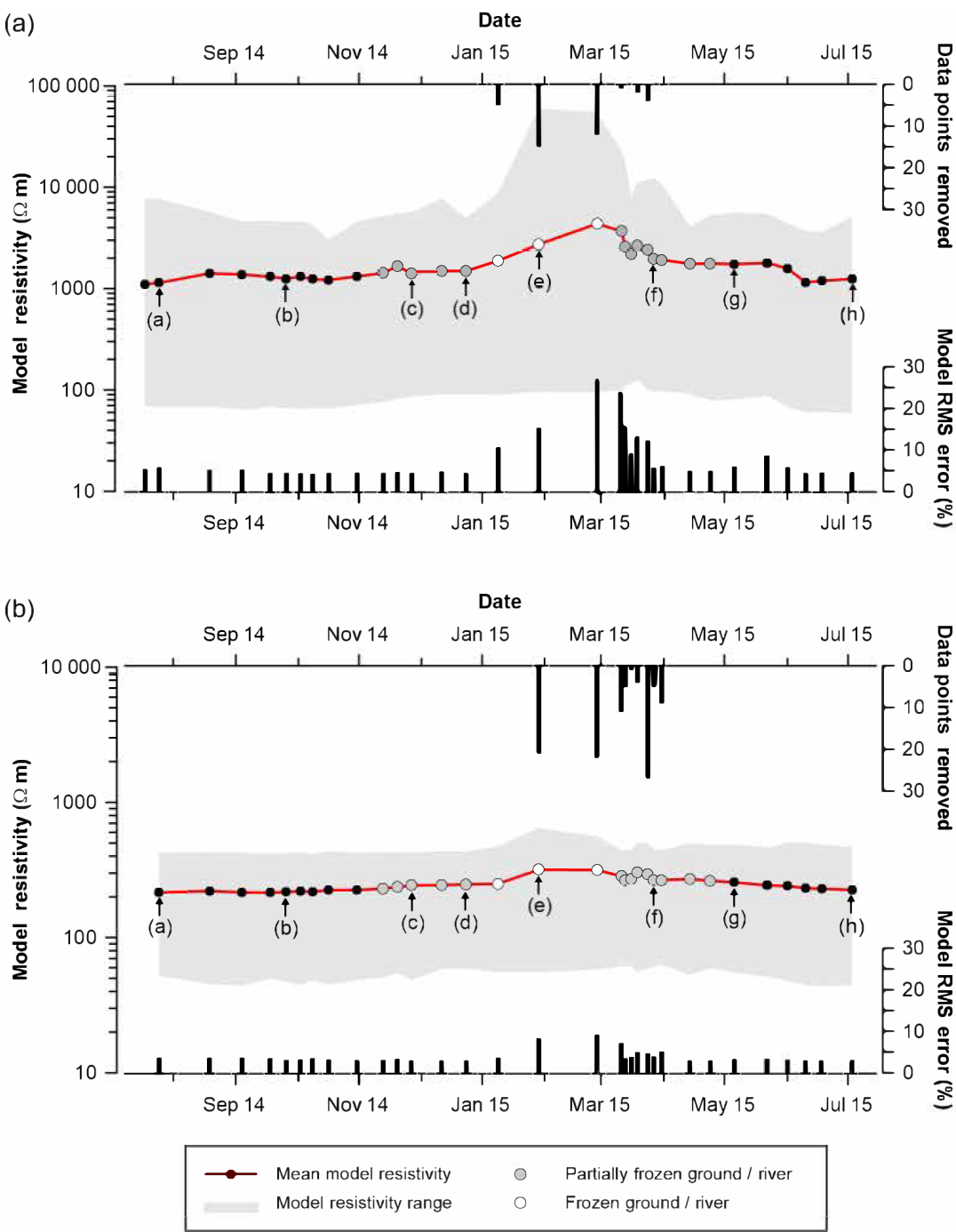

Figure 9. Temporal variations in inverted resistivity models for (a) pool and (b) riffle. Black dots represent unfrozen conditions and grey dots indicate partially frozen conditions, while white dots indicate completely frozen river conditions. Select resistivity models along the time series are shown in Fig. 10a-h.

the surface water body represented in the model, potentially contributing to the higher RMS errors along with the overall noisier measurements during this time (Fig. 9). The arrival of seasonal thaw conditions on 27 March 2015 was accompanied by reduced resistivities across the river as rock and river ice progressively thawed and was mobilized by spring freshet. Further seasonal warming on 6 May and 3 July 2015 resulted in a systematic decrease in riverbed resistivity from the northern to southern shoreline.

Riverbed resistivity across the riffle portion of the river (Fig. 10a-h) was markedly different with respect to the distribution and magnitude of resistivity fluctuations. The riffle exhibited a zone of comparatively low resistivity $(<100 \Omega \mathrm{m})$ that extended slightly deeper than that at the pool, to a depth of $3 \mathrm{~m}$. The initial survey on 26 July 2014 identified a zone of very low resistivity that progressively became more resistive over time (26 September through 24 December 2014). Much like the pool, however, this low resistivity zone reverted back toward the northern shoreline. The onset of seasonally frozen river conditions was accompanied by an increase in resistivity across a significant portion of the riverbed. Inverse models during frozen water conditions were again accompanied by higher RMS errors, which we attribute to the formation of river ice. Unlike the pool, which experienced the formation of a substantial zone of ground frost along the southern shore, less ground frost was observed at depth along the riverbanks bounding the riffle. Spring thaw brought reduced resistivities across the riverbed with subtle lateral variations, followed by the beginnings of a less-resistive riverbed zone emanating southward from the northern shoreline. The bedrock resistivity below $3 \mathrm{~m}$ depth remained relatively constant throughout the monitoring period. 
(a)

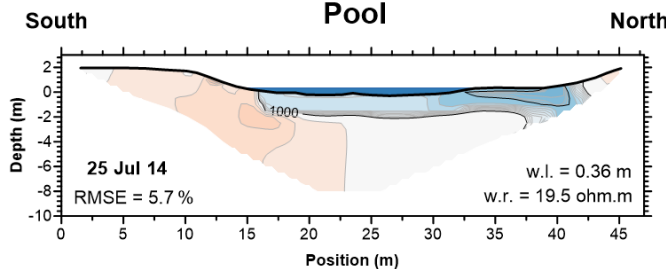

(b)

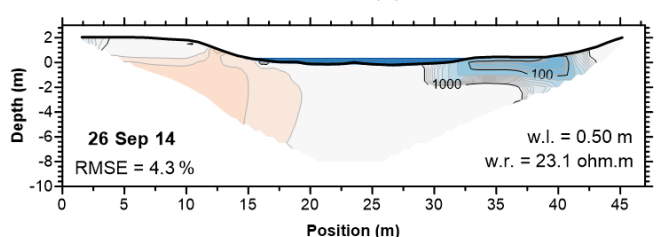

(c)

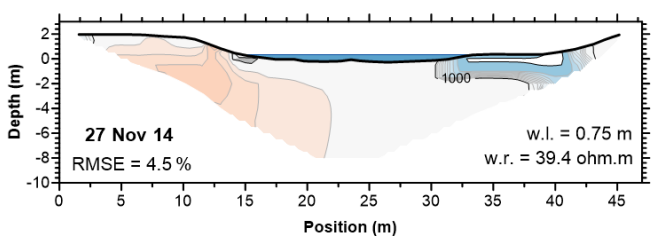

(d)

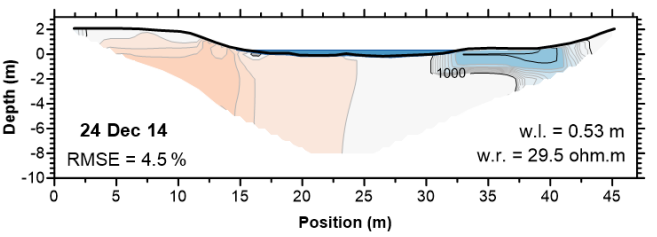

(e)

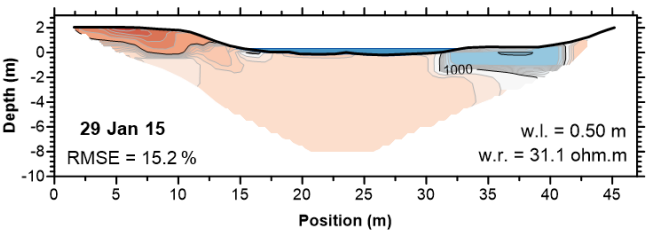

(f)

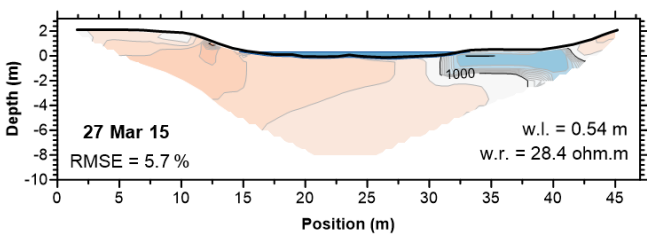

(g)

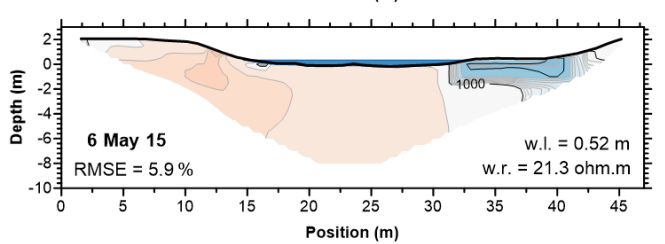

(h)

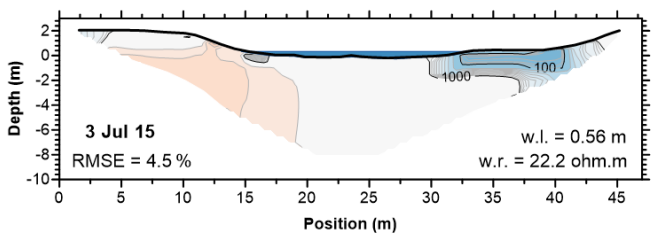

Model resistivity $(\Omega \mathrm{m})$

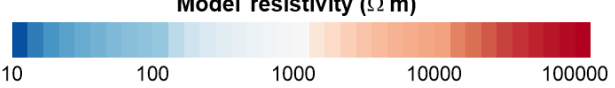

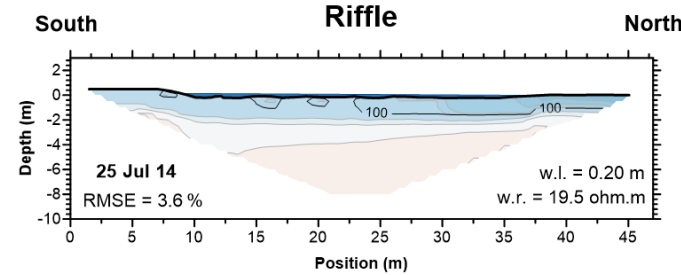
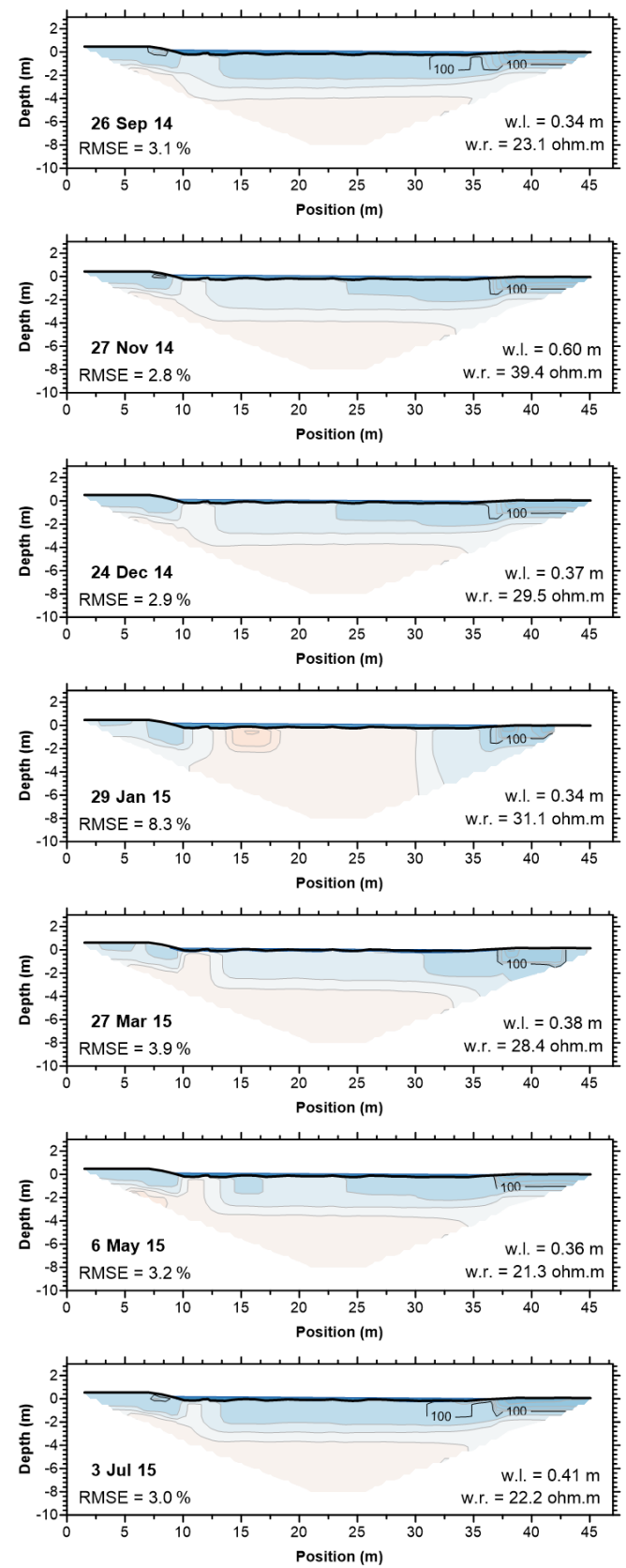

Model resistivity $(\Omega \mathrm{m})$

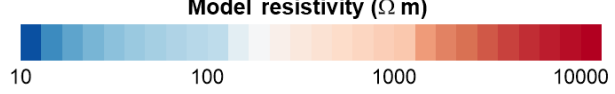

Figure 10. Representative inverse resistivity models across the pool and riffle, orientated from south to north. Datasets (a-h) are identified in Fig. 9. River stage (w.1.) and surface water resistivity (w.r.) values were fixed in the inverse model. A marked increase in resistivity was observed beneath the river during colder seasonal conditions (November through March), while lower resistivities were observed during warmer seasonal conditions (July). 
(a)
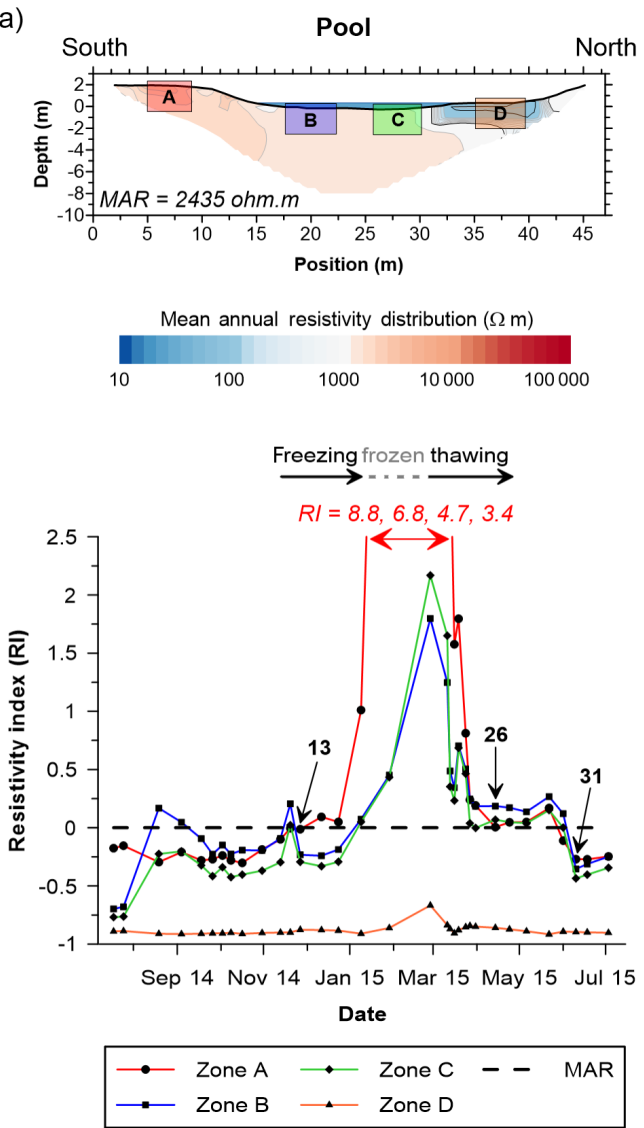

(b)
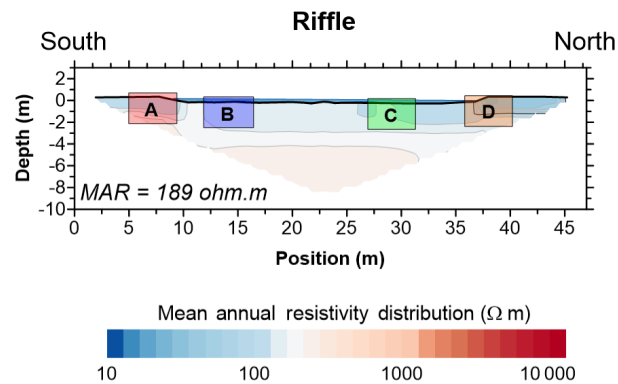

$\stackrel{\text { Freezing frozen thawing }}{\longrightarrow}$

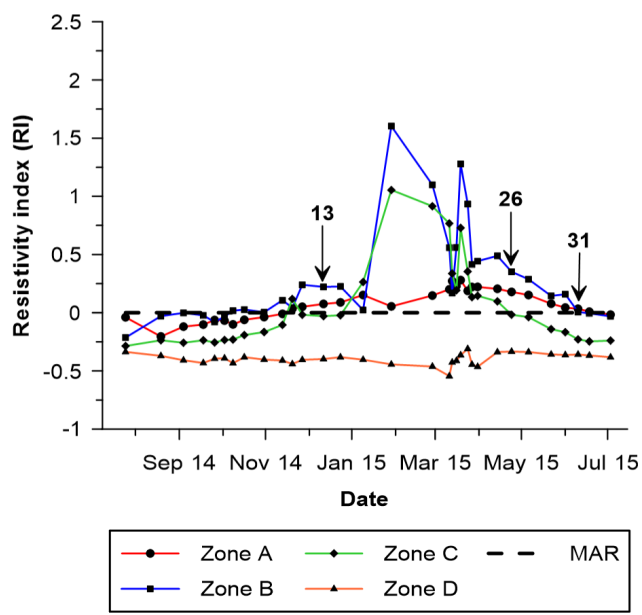

Figure 11. Spatiotemporal fluctuations in resistivity within the focused monitoring zones A, B, C, and D. The resistivity index (RI) was calculated using Eq. (3), using the mean zone resistivity (MZR) for a given measurement date and the mean annual resistivity (MAR) of the whole profile.

\subsubsection{Spatiotemporal resistivity trends}

A resistivity index was calculated using Eq. (3) to compare spatiotemporal variations in electrical resistivity within predefined zones of the bedrock beneath the river (Fig. 11); zones $\mathrm{A}$ and $\mathrm{D}$ represent conditions along the south and north riverbank, while zones $\mathrm{B}$ and $\mathrm{C}$ represent conditions within the southern and northern portions the river. These zones were defined based on their representative areas and the magnitude of the temporal fluctuations observed over the full monitoring period (Fig. 10). A RI of zero indicates a mean zone resistivity (MZR) that is equal to the mean annual resistivity (MAR) of the whole profile. An index of +1 indicates a resistivity that is twice the annual mean, while an index of -0.5 indicates a resistivity that is half the annual mean.

The RI time series for the pool (Fig. 11a) and riffle (Fig. 11b) capture the magnitude and frequency of the temporal variability observed within these four zones. Relative to the MAR, the pool exhibited larger and more frequent fluctuations in resistivity compared to the riffle. The southern shoreline (zone A) at the pool was more dynamic than the corresponding zone at the riffle; zone A at the pool encompasses a larger unsaturated zone, which is more likely impacted by changes in temperature and saturation, especially during the freezing and thawing period. The northern shoreline (zone D) at the pool and riffle exhibited lower-thanaverage resistivities with relatively minimal transience over the study period, with the exception of the mid-to-late-winter freeze-up. Here, a variable layer of sediment and organic matter with higher water content likely moderated freezethaw fluctuations relative to sections of exposed rock. Conditions below the riverbed (zones B and C) exhibited both longer-period (seasonal) and shorter-period (intraseasonal) fluctuations. While the relative changes observed at the pool were larger than the riffle, similar seasonal trends were observed at each location. Zones B and C at the pool were mutually consistent, while those at the riffle were less consistent.

Although perturbations were observed in the resistivity beneath the riverbed before and after winter freeze-up (e.g., zones $\mathrm{B}$ and $\mathrm{C}$ ), the responses were dampened relative to the winter period. Events 13, 26, and 31 (Fig. 6), which correspond to periods of increase precipitation, may coincide with observed perturbations in the RI; however, based on these 
data it is not clear whether the riverbed resistivity and surface water responses are mutually consistent. Here, a limited relationship may suggest that groundwater-surface water interaction does not occur in this section of the river or that groundwater discharge is strong enough to limit potential groundwater-surface water mixing at this particular location. Therefore, these observed geophysical dynamics within the riverbed may be more associated with seasonal temperature transience, with secondary influence due to solute-based fluctuations.

\section{Discussion}

\subsection{Influence of water properties on formation resistivity}

Riverbed electrical resistivity mapping during low and high stage periods identified a spatiotemporal response within the upper $6 \mathrm{~m}$ of rock, with the southern cut bank exhibiting a reduction in resistivity while the remaining portions of the river increased in resistivity. This spatiotemporal response, together with observed bedrock surface conditions, indicates that riverbed morphology strongly impacts groundwater dynamics below the riverbed.

Long-term resistivity monitoring along the fixed profiles over the pool and riffle portions of the river revealed a transient zone within the upper 2 and $3 \mathrm{~m}$ of bedrock, respectively. In particular, the formation of a low resistivity zone (high electrical conductivity) was observed during the warmer summer period that diminished as the environment cooled. While pore water conductivity depends on electrolytic concentration and temperature, their independent variability could not be decoupled across the entire study area given in situ sensor deployment limitations in a bedrock environment. Although this uncertainty in the driving mechanism of observed electrical changes below the riverbed hindered our ability to definitively define the vertical extent of a potential groundwater-surface water mixing zone, our geophysical dataset does suggest that a groundwater-surface water mixing in a bedrock environment may be more limited due to the lower effective porosity of rock and heterogeneous and anisotropic fracture distributions.

Aqueous temperature and specific conductance measurements collected in the river stage gauge (RSG1) and shallow bedrock well (SCV6) provided end-member conditions (Fig. 6). These data were used to assess the influence of aqueous conditions on bulk formation resistivity (Fig. 7). While some degree of overlap was observed between groundwater and surface water properties, they were generally differentiable across the study area. That being said, aqueous temperature fluctuations dominated the bulk electrical response over the full annual cycle. Given the impact of temperature on the bulk formation resistivity, observed bedrock resistivity dynamics are attributed to changes in formation water temperature, with secondary effects caused by changes in electrolytic concentration. These findings are consistent with Musgrave and Binley (2011), who concluded that temperature fluctuations over an annual cycle within a temperate wetland environment, with groundwater electrical conductivities ranging from 400 to $850 \mu \mathrm{S} \mathrm{cm}^{-1}$, dominated formation resistivity transience. Of course, as our annual temperature range was more extreme than that of Musgrave and Binley, we examined electrical dynamics within a less-porous, more heterogeneous and anisotropic medium and captured a broader range of seasonal conditions including ground frost and riverbed ice formation.

Measurements collected with a shorter time step (diurnal) and shorter electrode spacing may have captured more transient rainfall or snowpack melt episodes focused along discrete fracture pathways, possibly leading to the identification of electrolytic-induced transients beneath the riverbed, which would be more indicative of a groundwater-surface water mixing zone. Based on the short period of intraseasonal fluctuations observed in Fig. 11, and the timing and duration of major precipitation or thawing events (5 to 7 day cycles; Fig. 4), it is reasonable to assume that our geophysical time step (days to weeks) was accompanied by some degree of aliasing. Finally, it is possible that shallower sections of rock within the river exposed to direct sunlight during the day, which can vary depending on cloud cover (daily) and the Sun's position in the sky (seasonally), may have exhibited a wider range, or more transient temperature fluctuations, than those areas beneath or adjacent to a canopy. A closer inspection of the unfrozen temporal response in zone B reveals a wider range in resistivity relative to the more northern zone C. At this latitude in the Northern Hemisphere the southern shore will receive more direct sunlight; therefore, it is possible that the shallow rock on this side of the river experienced greater fluctuations in temperature (both seasonally and diurnally), thereby contributing to the observed geoelectrical dynamics. Although diurnal fluctuations in surface water temperature can be significant $\left(>10^{\circ} \mathrm{C}\right.$; e.g., Constantz et al., 1994; Constantz, 1998), the relative effects of such transient temperature fluctuations on our geophysical measurements cannot be assessed given our more seasonally scaled measurement sampling interval.

\subsection{Formation of ground frost and anchor ice}

A dramatic increase in bedrock resistivity was observed with the onset of freezing ground conditions; this can impact a wide range of infrastructure (e.g., dams, hydropower generation), ecologic (e.g., alteration of fish and benthic habitats), and hydraulic functions (e.g., river storage, baseflow) (Beltaos and Burrell, 2015). The formation of a highly resistive zone consistent with a seasonal frost front within the unsaturated portion of the riverbank (Fig. 10e; zone A in Fig. 11a), as well as the accumulation of river ice, resulted in marked changes in resistivity. These winter-season effects 
are readily evident in Fig. 11 at the pool and riffle. Here, the magnitude of the resistivity increase may reflect a potential reduction in the hydraulic connectivity between surface water and groundwater during the winter months.

Ground frost primarily formed along the riverbank over the southern floodplain at the pool. This topographically higher area was relatively devoid of large shrubs and trees (Fig. 2), and thus likely experienced more severe weather conditions (e.g., higher winds resulted in less snow pack to insulate the ground). These conditions would promote the formation of a thicker frost zone which propagated to the water table (pool in Fig. 10e). The adjacent northern riverbank and those up-gradient at the riffle were topographically lower (i.e., thinner unsaturated zone) and were sheltered by large trees. The formation of a seasonal frost zone along the riverbank may have implications to baseflow dynamics during the winter months and the early-thaw period.

A simple sensitivity analysis of the inversion process using different constraints on surface water geometry and aqueous electrical resistivity indicated that model convergence was highly sensitive to surface water geometry and aqueous resistivity. For instance, setting an aqueous resistivity of one-half the true value led to poor model convergence and unrealistic resistivity values for bedrock. The riffle was relatively less sensitive to surface water properties, likely because of its overall lower river stage compared to the pool and, hence, relatively lower impact of the surface water body on the apparent resistivity measurement. This sensitivity to surface water properties is a consequence of the high electrical conductivity of the surface water relative to high resistivity bedrock.

Anchor ice reduced the electrical connectivity across the riverbed, while the ice crust along the surface of the water altered the effective geometry of the water body, further influencing the inverse solution. While the formation of river ice was accompanied by higher RMS errors at the pool (>6\%) and riffle ( $>4 \%$; Fig. 9), direct measurements of river ice thickness and spatial extent could not be collected or explicitly incorporated into the surface water layer geometry during the winter months.

\subsection{Implications to the conceptualization of groundwater-surface water exchange in bedrock rivers}

The fractured dolostone in this study consists of a visible orthogonal joint network approximately orientated at 10 to $20^{\circ}$ north-northwest and 280 to $290^{\circ}$ south-northwest, consistent with the regional joint orientations, with frequencies ranging from centimetre to sub-metre scale. Streambed resistivity measurements indicate a seasonally dynamic groundwater zone within the upper 2 to $3 \mathrm{~m}$ of riverbed. A less-resistive zone $(<1000 \Omega \mathrm{m})$ was observed beneath the pool emanating from the northern shoreline during warmer low-flow periods (July and August 2014). This zone retracted in late sum- mer but showed signs of reappearance in early July 2015 . A similarly evolving low-resistivity zone $(<100 \Omega \mathrm{m})$ was observed across the riffle, but was more variable across the river transect. Although dynamic fluctuations in temperature and aqueous conductivity support the potential existence of a groundwater-surface water mixing zone, it is not yet clear how these geoelectrical dynamics were influenced or enhanced by fluid flow in the discrete fractures, exchange between the mobile and immobile pore phase, and seasonal thermal gradients across the riverbed.

Discrete fracture networks and dissolution-enhanced features will result in a more heterogeneous and anisotropic groundwater-surface water mixing zones compared to porous unconsolidated sediment. Swanson and Cardenas (2010) examined the utility of using heat as a tracer of groundwater-surface water exchange across a pool-rifflepool sequence. Observed thermal patterns and zones of influence (i.e., effective mixing zones) in their study were consistent with conceptual models depicting a pool-riffle-pool sequence. While similar temperature dynamics may be expected across the pool-riffle-pool sequence in a bedrock environment, our coarser temporal sampling interval (days to weeks) combined with our smoothed resistivity models limited our ability to capture subtle diel temperature transience across discrete fractures or flow features. Although the electrical resistivity method was not able to definitively differentiate between groundwater and surface water, our geophysical measurements do provide insight into the magnitude, lateral extent, and spatiotemporal scale of geoelectrical transience, which are largely driven by temperature fluctuations within the upper few metres of rock.

\section{Conclusions}

Time-lapse resistivity measurements were performed across a $200 \mathrm{~m}$ reach of the Eramosa River during low and highstage periods. Our results showed high spatiotemporal variability within the riverbed that could be attributed to its exposure of the bedding plane and vertical fracture, as well as the morphology or competency of the rock surface. Complementary fracture and temperature profiling within the open and lined borehole revealed abundant active groundwater flow zones spanning the upper $8-10 \mathrm{~m}$ of bedrock, with strong intra-seasonal and seasonal temperature variations along horizontal fracture sets. While surface resistivity profiles captured geoelectrical dynamics within the upper few metres of rock, these data represent indirect evidence of riverbed transience resulting from changes in groundwater temperature and specific conductance. Geoelectrical transience was primarily governed by seasonal temperature trends, with secondary effects arising from porewater conductance; however, spatiotemporal variations in temperature and specific conductance could not be decoupled beyond the fixed monitoring points. 
Time-lapse electrical resistivity imaging of the pool and riffle portion of the river, sampled on a semi-daily to semiweekly interval, showed consistently higher resistivity at the pool, with more elevated resistivities along the southern shoreline. Seasonal cooling was accompanied by the formation of a higher-resistivity zone emanating from the southern shore to northern shore in both the pool and riffle. This resistivity trend reversed during the seasonal warming cycle, becoming less resistive toward the southern shoreline as seasonal temperatures increased and river stage decreased. The formation of ground frost and basal ice along the riverbed had a strong impact on the seasonal resistivity profiles during the winter months. Intraseasonal (i.e., spring, summer, fall) geoelectrical changes beneath the riverbed were strongly dependent upon seasonal temperature trends, with the pool and riffle exhibiting variable horizontal and vertical zones of influence. Geoelectrical transience associated with major precipitation events, which were accompanied by short-period perturbations in surface water temperature and specific conductance, had a relatively small impact on sub-riverbed resistivity. This could be explained by a seasonally sustained groundwater discharge zone across this reach of the river, which would have limited or moderated electrical resistivity changes associated with surface water mixing with groundwater.

This study demonstrated that time-lapse resistivity measurements have the capacity to image the magnitude and scale of transience within a bedrock riverbed. Although riverbed resistivity dynamics were largely a function of seasonal atmospheric temperature trends, the ability to map the geometrical extent of such heterothermic zones beneath a river would be relevant to understanding biogeochemical processes, benthic activity, and macro-scale hyporheic zone processes. Imaging the magnitude and scale of transience within the riverbed will be critical to the advancement of our understanding of mechanisms controlling groundwatersurface water exchange within fractured bedrock rivers. Given the challenges and costs associated with installing sensors within rock and effectively sampling a heterogeneous flow system, minimally invasive surface and borehole geophysical methods offer an ideal alternative and possibly a more effective approach for long-term groundwatersurface water monitoring of bedrock environments, by reducing instrumentation costs and impacts to ecosensitive environments.

Data availability. The data used in this study are presented in the figures. Complete monitoring datasets (Figs. 9 and 10) can be made available upon request from the corresponding author.

Author contributions. CMS designed the experiment, conducted the surveys, and analyzed the geophysical data. CSK designed the borehole network, logged the core, instrumented the hydrological monitoring network. DCC designed and collected the temperature profiles, logged the core and supported hydrological data collection and interpretation. BLP contributed to the design of the hydrological geophysical monitoring network and supported conceptual understanding of groundwater flow through fractured rock.

Competing interests. The authors declare that they have no conflict of interest.

Acknowledgements. This research was made possible through funding by the Natural Sciences and Engineering Research Council of Canada in the form of a Banting Fellowship to Colby M. Steelman, and an Industrial Research Chair (grant no. IRCPJ363783-06) to Beth L. Parker. The authors are very appreciative of the field contributions of staff and students at the University of Guelph and University of Waterloo, particularly field technicians Dan Elliot and Bob Ingleton. This work would not have been possible without land-access agreements with Scouts Canada and the Ontario Ministry of Natural Resources and river-flow data provided by the Grand River Conservation Authority.

Edited by: Mauro Giudici

Reviewed by: three anonymous referees

\section{References}

Alexander, M. D. and Caissie, D.: Variability and comparison of hyporheic water temperatures and seepage fluxes in a small Atlantic Salmon stream, Ground Water, 41, 72-82, 2003.

Anderson, M. P.: Heat as a ground water tracer, Ground Water, 43, 951-968, 2005.

Archie, G. E.: The electrical resistivity log as an aid in determining some reservoir characteristics, T. Am. Inst. Mineral. Metall. Petrol. Eng., 146, 54-62, 1942.

Arps, J. J.: The effect of temperature on the density and electrical resistivity of sodium chloride solutions, Trans. A.I.M.E., 164, 54-62, 1953.

Beltaos, S. and Burrell, B. C.: Hydrotechnical advances in Canadian river ice science and engineering during the past 35 years, Can. J. Civil. Eng., 42, 583-591,https://doi.org/10.1139/cjce2014-0540, 2015.

Bianchin, M. S., Smith, L., and Beckie, R. D.: Defining the hyporheic zone in a large tidally influenced river, J. Hydrol., 406, 16-29, https://doi.org/10.1016/j.jhydrol.2011.05.056, 2011.

Binley, A., Ullah, S. Heathwaite, A. L., Heppell, C., Byrne, P., Lansdown, K., Trimmer, M., and Zhang, H.: Revealing the spatial variability of water fluxes at the groundwatersurface water interface, Water Resour. Res., 49, 3978-3992, https://doi.org/10.1002/wrcr.20214, 2013.

Boano, F., Revelli, R., and Ridolfi L.: Reduction of the hyporheic zone volume due to the stream-aquifer interaction, Geophys. Res. Lett., 35, L09401, https://doi.org/10.1029/2008GL033554, 2008.

Brassington, R.: Field Hydrogeology, John Wiley \& Sons, Inc, Chichester, 1998.

Briggs, M. A., Lautz, L. K., McKenzie, J. M., Gordon, R. P., and Hare, D. K.: Using high-resolution distributed tem- 
perature sensing to quantify spatial and temporal variability in vertical hyporheic flux, Water Resour. Res., 48, W02527, https://doi.org/10.1029/2011WR011227, 2012.

Brunton, F. R.: Update of revisions to the Early Silurian stratigraphy of the Niagara Escarpment: integration of sequence stratigraphy, sedimentology and hydrogeology to delineate hydrogeologic units, in: Summary of Field Work and Other Activities 2009, Ontario Geologic Survey, Open File Report 6240, 25-125-20, 2009.

Campbell, R. B., Bower, C. A., and Richards, L. A.: Change of electrical conductivity with temperature and the relation of osmotic pressure to electrical conductivity and ion concentration for soil extracts, Soil Sci. Soc. Am. Proc., 12, 66-69, 1948.

Cardenas, M. B. and Markowski, M. S.: Geoelectrical imaging of hyporheic exchange and mixing of river water and groundwater in a large regulated river, Environ. Sci. Technol., 45, 1407-1411, https://doi.org/10.1021/es103438a, 2011.

Cole, J., Coniglio, M., and Gautrey, S.: The role of buried bedrock valleys on the development of karstic aquifers in flat-lying carbonate bedrock: insights from Guelph, Ontario, Canada, Hydrogeol. J., 17, 1411-1425, https://doi.org/10.1007/s10040-0090441-3, 2009

Conant Jr., B.: Delineating and quantifying ground water discharge zones using streambed temperature, Ground Water, 42, 243-257, 2004.

Constantz, J.: Interaction between stream temperature, streamflow, and groundwater exchanges in alpine streams, Water Resour. Res., 34, 1609-1615, 1998.

Constantz, J.: Heat as a tracer to determine streambed water exchanges, Water Resour. Res., 44, W00D10, https://doi.org/10.1029/2008WR006996, 2008.

Constantz, J., Thomas, C. L., and Zellweger, G.: Influence of diurnal variations in stream temperature on streamflow lows and groundwater recharge, Water Resour. Res., 30, 3253-3264, 1994.

Coscia, I., Greenhalgh, S. A., Linde, N., Doetsch, J., Marescot, L., Günther, T., Vogt, T., and Green, A. G.: 3D crosshole ERT for aquifer characterization and monitoring of infiltrating river water, Geophysics, 76, G49-G59, https://doi.org/10.1190/1.3553003, 2011.

Coscia, I., Linde, N., Greenhalgh, S., Vogt, T., and Green, A.: Estimating traveltimes and groundwater flow pattern using 3D timelapse crosshole ERT imaging of electrical resistivity fluctuations induced by infiltrating river water, Geophysics, 77, E239-E250, https://doi.org/10.1190/GEO2011-0328.1, 2012.

Crook, N., Binley, A., Knight, R., Robinson, D. A., Zarnetske, J., and Haggerty, R.: Electrical resistivity imaging of the architecture of substream sediments, Water Resour. Res., 44, W00D13, https://doi.org/10.1029/2008WR006968, 2008.

Crosbie, R. S., Taylor, A. R., Davis, A. C., Lamontagne, S., and Munday, T.: Evaluation of infiltration from losing-disconnected rivers using a geophysical characterisation of the riverbed and a simplified infiltration model, J. Hydrol., 508, 102-113, https://doi.org/10.1016/j.jhydrol.2013.07.045, 2014.

Doveton, J. H.: Log analysis of subsurface geology: concepts and computer methods, Wiley-Interscience, New York, 1986.

Dimova, T. N., Swarzenski, P. W., Dulaiova, H., and Glenn, C. R.: Utilizing multichannel electrical resistivity methods to examine the dynamics of the fresh water-seawater interface in two
Hawaiian groundwater systems, J. Geophys. Res., 117, C02012, https://doi.org/10.1029/2011JC007509, 2012.

Doetsch, J., Linde, N., Vogt, T., Binley, A., and Green, A. G.: Imaging and quantifying salt-tracer transport in a riparian groundwater system by means of 3D ERT monitoring, Geophysics, 77, B207-B218, https://doi.org/10.1190/GEO2012-0046.1, 2012.

Doro, K. O., Leven, C., and Cirpka, O. A.: Delineating subsurface heterogeneity at a loop of River Steinlach using geophysical and hydrogeological methods, Environ. Earth Sci., 69, 335-348, https://doi.org/10.1007/s12665-013-2316-0, 2013.

Ellis, D. V.: Well logging for earth scientists, Elsevier Science Publishing Company, Inc., New York, 1987.

Evans, E. C., Greenwood, M. T., and Petts, G. E.: Thermal profiles within river beds, Hydrol. Process., 9, 19-25, 1995.

Fan, Y., Toran, L., and Schlische, R. W.: Groundwater flow and groundwater-stream interaction in fractured and dipping sedimentary rocks: insights from numerical models, Water Resour. Res., 43, W01409, https://doi.org/10.1029/2006WR004864, 2007.

Froese, D. G., Smith, D. G., and Clement, D. T.: Characterizing large river history with shallow geophysics: middle Yukon River, Yukon Territory and Alaska, Geomorphology, 67, 391406, https://doi.org/10.1016/j.geomorph.2004.11.011, 2005.

Glover, P. W. J.: A generalized Archie's law for $\mathrm{n}$ phases, Geophysics, 75, E247-E265, https://doi.org/10.1190/1.3509781, 2010.

Gourry, J.-C., Vermeersch, F., Garcin, M., and Giot, D.: Contribution of geophysics to the study of alluvial deposits: a case study in the Val d'Avaray area of the River Loire, France, J. Appl. Geophys., 54, 35-49, https://doi.org/10.1016/j.jappgeo.2003.07.002, 2003.

Harrington, G. A., Gardner, W. P., and Munday, T. J.: Tracking groundwater discharge to a large river using tracers and geophysics, Ground Water, 52, 837-852, https://doi.org/10.1111/gwat.12124, 2014.

Hatch, C. E., Fisher, A. T., Revenaugh, J. S., Constantz, J., and Ruehl, C.: Quantifying surface water-groundwater interactions using time series analysis of streambed thermal records: Method development, Water Resour. Res., 42, W10410, https://doi.org/10.1029/2005WR004787, 2006.

Irvine, D. J., Briggs, M. A., Lautz, L. K., Gordon, R. P., McKenzie, J. M., and Cartwright, I.: Using diurnal temperature signals to infer vertical groundwater-surface water exchange, Ground Water, 55, 10-26, https://doi.org/10.1111/gwat.12459, 2016.

Johnson, T. C., Slater, L. D., Ntarlagiannis, D., Day-Lewis, F. D., and Elwaseif, M.: Monitoring groundwater-surface water interaction using time-series and time-frequency analysis of transient three-dimensional electrical resistivity changes, Water Resour. Res., 48, W07506, https://doi.org/10.1029/2012WR011893, 2012.

Käser, D. H., Binley, A., and Heathwaite, A. L.: On the importance of considering channel microforms in groundwater models of hyporheic exchange, River Res. Appl., 29, 528-535, https://doi.org/10.1002/rra.1618, 2013.

Keery, J., Binley, A., Crook, N., and Smith, J. W. N.: Temoral and spatial variability of groundwater-surface water fluxes: Development and application of an analytical method using temperature time series, J. Hydrol., 336, 1-16, https://doi.org/10.1016/j.jhydrol.2006.12.003, 2007. 
Keller, G. V.: Section V: Electrical properties, in: CRC Practical handbook of physical properties of rock and minerals, edited by: Carmichael, R. S., CRC Press, 361-427, 1989.

Keller, C., Cherry, J. A., and Parker, B. L.: New method for continuous transmissivity profiling in fractured rock, Ground Water, 52, 352-367, https://doi.org/10.1111/gwat.12064, 2014.

Knight, R. J. and Endres, A. L.: Chapter 3: An Introduction to Rock Physics Principles for Near-Surface Geophysics, in: NearSurface Geophysics, Society of Exploration Geophysics, edited by: Butler, D. K., Tulsa, Oklahoma, 31-70, 2005.

Kunert, M. and Coniglio, M.: Origin of vertical shafts in bedrock along the Eramosa River valley near Guelph, southern Ontario, Can. J. Earth Sci., 39, 43-52, https://doi.org/10.1139/E01-053, 2002.

Kunert, M., Coniglio, M., and Jowett, E. C.: Controls and age of cavernous porosity in Middle Silurian dolomite, southern Ontario, Can. J. Earth Sci., 35, 1044-1053, 1998.

Lemieux, J.-M., Kirkwood, D., and Therrien, R.: Fracture network analysis of the St-Eustache quarry, Quebec, Canada, for groundwater resources management, Can. Geotech. J., 46, 828-841, 2009.

Loke, M. H.: Tutorial: 2-D and 3-D electrical imaging surveys, Geotomo Software, Malaysia, 2002.

Loke, M. H. and Dahlin, T.: A comparison of the Gauss-Newton and quasi-Newton methods in resistivity imaging inversion, J. Appl. Geophys., 49, 149-162, 2002.

Loke, M. H., Chambers, J. E., Rucker, D. F., Kuras, O., and Wilkinson, P. B.: Recent developments in the direct-current geoelectrical imaging method, J. Appl. Geophys., 95, 135-156, https://doi.org/10.1016/j.jappgeo.2013.02.017, 2013.

McLaren, R. G., Sudicky, E. A., Park, Y.-J., and Illman, W. A.: Numerical simulation of DNAPL emissions and remediation in a fractured dolomitic aquifer, J. Contam. Hydrol., 136-137, 5671, https://doi.org/10.1016/j.jconhyd.2012.05.002, 2012.

McNeill, J. D.: Electromagnetic terrain conductivity measurement at low induction numbers, Geonics Ltd. Technical Note, TN-6, Mississauga, Ontario, 1980.

Meyer, J. R., Parker, B. L., and Cherry, J. A.: Detailed hydraulic head profiles as essential data for defining hydrogeologic units in layered fractured sedimentary rock, Environ. Geol., 56, 27-44, https://doi.org/10.1007/s00254-007-1137-4, 2008.

Meyerhoff, S. B., Karaoulis, M., Fiebig, F., Maxwell, R. M., Revil, A., Martin, J. B., and Graham, W. D.: Visualization of conduit-matrix conductivity differences in a karst aquifer using time-lapse electrical resistivity, Geophys. Res. Lett., 39, L24401, https://doi.org/10.1029/2012GL053933, 2012.

Meyerhoff, S. B., Maxwell, R. M., Revil A., Martin, J. B., Karaoulis, M., and Graham, W. D.: Characterization of groundwater and surface water mixing in a semiconfined karst aquifer using time-lapse electrical resistivity tomography, Water Resour. Res., 50, 2566-2585, https://doi.org/10.1002/2013WR013991, 2014.

Miller, C. R., Routh, P. S., Brosten, T. R., and McNamara, J. P.: Application of time-lapse ERT imaging to watershed characterization, Geophysics, 73, G7-G17, https://doi.org/10.1190/1.2907156, 2008.

Musgrave, H. and Binley, A.: Revealing the temporal dynamics of subsurface temperature in a wetland su- ing time-lapse geophysics, J. Hydrol., 396, 258-266, https://doi.org/10.1016/j.jhydrol.2010.11.008, 2011.

Naegeli, M. W., Huggenberger, P., and Uehlinger, U.: Ground penetrating radar for assessing sediment structures in the hyporheic zone of a prealpine river, J. N. Am. Benthol. Soc., 15, 353-366, 1996.

Norman, F. A. and Cardenas, M. B.: Heat transport in hyporheic zones due to bedforms: An experimental study, Water Resour. Res., 50, 3568-3582, https://doi.org/10.1002/2013WR014673, 2014.

Novakowski, K. S. and Lapcevic, P. A.: Regional hydrogeology of the Silurian and Ordovician sedimentary rock underlying Niagara Falls, Ontario, Canada, J. Hydrol., 104, 211-236, 1998.

Nyquist, J., Freyer, P. A., and Toran, L.: Stream bottom resistivity tomography to map ground water discharge, Ground Water, 46, 561-569, https://doi.org/10.1111/j.1745-6584.2008.00432.x, 2008.

Orlando, L.: Some consideration on electrical resistivity imaging for characterization of waterbed sediments, J. Appl. Geophys., 95, 77-89, https://doi.org/10.1016/j.jappgeo.2013.05.005, 2013.

Oxtobee, J. P. A. and Novakowski, K.: A field investigation of groundwater/surface water interaction in a fractured bedrock environment, J. Hydrol., 269, 169-193, 2002.

Oxtobee, J. P. A. and Novakowski, K. S.: Ground water/surface water interaction in a fractured rock aquifer, Ground Water, 41, 667681, 2003.

Pehme, P. E., Parker, B. L., Cherry, J. A., and Greenhouse, J. P.: Improved resolution of ambient flow through fractured rock with temperature logs, Ground Water, 48, 191-205, https://doi.org/10.1111/j.1745-6584.2009.00639.x, 2010.

Pehme, P. E., Parker, B. L., Cherry, J. A., and Blohm, D.: Detailed measurement of the magnitude and orientation of thermal gradients in lined coreholecoreholes for characterizing groundwater flow in fractured rock, J. Hydrol., 513, 101-114, https://doi.org/10.1016/j.jhydrol.2014.03.015, 2014.

Perrin, J., Parker, B. L., and Cherry, J. A.: Assessing the flow regime in a contaminated fractured and karstic dolostone aquifer supplying municipal water, J. Hydrol., 400, 396-410, https://doi.org/10.1016/j.jhydrol.2011.01.055, 2011.

Reynolds, J. M.: An Introduction to Applied and Environmental Geophysics, 2nd Edn., John Wiley \& Sons, Chichester, 2011.

Rhoades, J. D., Raats, P. A. C., and Prather, R. J.: Effect of liquidphase electrical conductivity, water content, and surface conductivity on bulk soil electrical conductivity, Soil Sci. Soci. Am. J., 40, 651-655, 1976.

Rucker, D. F., Noonan, G. E., and Greenwood, W. J.: Electrical resistivity in support of geological mapping along the Panama Canal, Eng. Geol., 117, 121-133, 2011.

Sambuelli, L., Leggieri, S., Calzoni, C., and Porporato, C.: Study of riverine deposits using electromagnetic methods at a low induction number, Geophysics, 72, B113-B120, https://doi.org/10.1190/1.2754249, 2007.

Schmidt, C., Conant Jr., B., Bayer-Raich, M., and Schirmer, M.: Evaluation and field-scale application of an analytical method to quantify groundwater discharge using mapped streambed temperatures, J. Hydrol., 347, 292-307, https://doi.org/10.1016/j.jhydrol.2007.08.022, 2007.

Silliman, S. E. and Booth, D. F.: Analysis of time-series measurements of sediment temperature for identification of gaining vs. 
losing portions of Juday Creek, Indiana, J. Hydrol., 146, 131148, 1993.

Singha, K., Pidlisecky, A., Day-Lewis, F. D., and Gooseff, M. N. Electrical characterization of non-Fickian transport in groundwater and hyporheic systems, Water Resour. Res., 44, W00D07, https://doi.org/10.1029/2008WR007048, 2008.

Singha, K., Day-Lewis, F. D., Johnson, T., and Slater, L. D.: Advances in interpretation of subsurface processes with timelapse electrical imaging, Hydrol. Process., 29, 1549-1576, https://doi.org/10.1002/hyp.10280, 2015.

Sirieix, C., Riss, J., Rey, F., Prétou, F., and Lastennet, R.: Electrical resistivity tomography to characterize a karstic Vauclusian spring: Fontaine d'Orbe (Pyrénées, France), Hydrogeol. J., 22, 911-924, https://doi.org/10.1007/s10040-013-1095-8, 2014

Slater, L., Binley, A. M., Daily, W., and Johnson, R.: Cross-hole electrical imaging of a controlled saline tracer injection, J. Appl. Geophys., 44, 85-102, 2000.

Slater, L. D., Ntarlagiannis D., Day-Lewis, F. D., Mwakanyamale, K., Versteeg, R. J., Ward, A., Strickland, C., Johnson, C. D., and Lane Jr., J. W.: Use of electrical imaging and distributed temperature sensing method to characterize surface water-groundwater exchange regulating uranium transport at the Hanford 300 Area, Washington, Water Resour. Res., 46, W10533, https://doi.org/10.1029/2010WR009110, 2010.

Snieder, R. and Trampert, J.: Inverse problems in geophysics, in: Wavefield Inversion, edited by: Wirgin, A., Springer-Verlag, New York, 119-190, 1999.

Stickler, M. and Alfredsen, K. T.: Anchor ice formation in streams: a field study, Hydrol. Process., 23, 2307-2315, https://doi.org/10.1002/hyp.7349, 2009.

Steelman, C. M., Kennedy, C. S., and Parker, B. L.: Geophysical conceptualization of a fractured sedimentary bedrock riverbed using ground-penetrating radar and induced electrical conductivity, J. Hydrol., 521, 433-446, https://doi.org/10.1016/j.jhydrol.2014.12.001, 2015a.

Steelman, C. M., Parker, B. L., and Kennedy, C. S.: Evaluating local-scale anisotropy and heterogeneity along a fractured sedimentary bedrock river using EM azimuthal resistivity and ground-penetrating radar, J. Appl. Geophys., 116, 156-166, https://doi.org/10.1016/j.jappgeo.2015.03.003, 2015b.

Swanson, T. E. and Cardenas, M. B.: Diel heat transport within the hyporheic zone of a pool-riffle-pool sequence of a losing stream and evaluation of models for fluid flux estimation using heat, Limnol. Oceanogr., 55, 1741-1754, https://doi.org/10.4319/lo.2010.55.4.1741, 2010.

Tinkler, K. J. and Wohl, E. E.: Rivers over rock: fluvial processes in bedrock channels, Geophysical Monograph 17, American Geophysical Union, Washington, D.C., 1998.
Toran, L., Nyquist J. E., Fang, A. C., Ryan, R. J., and Rosenberry, D. O.: Observing lingering hyporheic storage using electrical resistivity: variations around stream restoration structures, Crabby Creek, PA, Hydrol. Process., 27, 1411-1425, https://doi.org/10.1002/hyp.9269, 2013a.

Toran, L., Hughes, B., Nyquist, J., and Ryan, R.: Freeze core sampling to validate time-lapse resistivity monitoring of the hyporheic zone, Ground Water, 51, 635-640, https://doi.org/10.1111/j.1745-6584.2012.01002.x, 2013b.

Wallin, E. L., Johnson, T. C., Greenwood, W. J., and Zachara, J. M.: Imaging high stage river-water intrusion into a contaminated aquifer along a major river corridor using 2-D time-lapse surface electrical resistivity tomography, Water Resour. Res., 49, 1693 1708, https://doi.org/10.1002/wrcr.20119, 2013.

Ward, A. S., Gooseff, M. N., and Singha, K.: Imaging hyporheic zone solute transport using electrical resistivity, Hydrol. Process., 24, 948-953, https://doi.org/10.1002/hyp.7672, 2010a.

Ward, A. S., Gooseff, M. N., and Singha, K.: Characterizing hyporheic transport processes - interpretation of electrical geophysical data in coupled stream-hyporheic zone systems during solute tracer studies, Adv. Water. Resour., 33, 1320-1330, https://doi.org/10.1016/j.advwatres.2010.05.008, 2010b.

Ward, A. S., Fitzgerald, M., Gooseff, M. N., Voltz, T. J., Binley, A. M., and Singha, K.: Hydrologic and geomorphic controls on hyporheic exchange during base flow recession in a headwater mountain stream, Water Resour. Res., 48, W04513, https://doi.org/10.1029/2011WR011461, 2012.

Waxman, M. H. and Smits, L. J. M.: Electrical conductivities in oilbearing shaly sands, Soc. Petrol. Eng. J., 8, 107-122, 1968.

White, D. S., Elzinga, C. H., and Hendricks, S. P.: Temperature patterns within the hyporheic zone of a northern Michigan river, J. N. Am. Benthol. Soc., 6, 85-91, 1987.

Woessner, W. W.: Stream and fluvial plain ground water interactions: rescaling hydrogeologic thought, Ground Water, 38, 423429, 2000.

Worthington, P. F.: The uses and abuses of the Archie equations, 1: The formation facture-porosity relationship, J. Appl. Geophys., 30, 215-228, 1993.

Zanini, L., Novakowski, K. S., Lapcevic, P., Bickerton, G. S., Voralek, J., and Talbot, C.: Ground water flow in a fractured carbonate aquifer inferred from combined hydrogeological and geochemical measurements, Ground Water, 38, 350-360, 2000. 